\title{
Embryonic ontogeny of three species of Horned Frogs, with a review of early development in Ceratophryidae
}

\author{
Jimena Grosso ${ }^{1}$ ( ) | Diego Baldo ${ }^{2}$ | Carolina Salgado Costa ${ }^{3}$ | \\ Guillermo S. Natale $^{3}$ | Florencia Vera Candioti ${ }^{1}$
}

${ }^{1}$ Unidad Ejecutora Lillo (CONICET-FML), San Miguel de Tucumán, Tucumán, Argentina

${ }^{2}$ Instituto de Biología Subtropical (IBS, CONICET-UNaM), Laboratorio de Genética Evolutiva, Facultad de Ciencias Exactas, Universidad Nacional de Misiones, Posadas, Misiones, Argentina

${ }^{3}$ Centro de Investigaciones del Medioambiente (CIM, UNLP-CONICET), Departamento de Química, Facultad de Ciencias Exactas, Universidad Nacional La Plata, La Plata, Buenos Aires, Argentina

\section{Correspondence}

Jimena Grosso, Unidad Ejecutora Lillo (CONICET-FML), San Miguel de Tucumán, Tucumán, Argentina.

Email: jime.grosso@gmail.com

Funding information

Agencia Nacional de Promoción Científica y Tecnológica, Grant/Award Numbers: PICT 2015_2381, PICT 2017_2437

\begin{abstract}
Horned Frogs of the family Ceratophryidae are conspicuous anurans represented by three endemic South American genera. Most ceratophryids inhabit semiarid environments, but three species of Ceratophrys occupy tropical or temperate humid areas. Several morphological and behavioral characters of larvae and adults are conserved across the family. Based on examination of specimens and accounts in the literature, the embryonic development of $C$. ornata, $C$. cranwelli, and the monotypic genus Chacophrys are described and compared with that of species of Lepidobatrachus. Ceratophryid embryos share a suite of morphological features and heterochronic shifts during development. Most features, such as gill structure, ciliation, early hatching, and precocious differentiation of the gut and hind limbs, are shared by all the species regardless the differences in the habitats that occupy. This is consistent with previous observations of some adult characters, and likely supports the hypothesis of an early diversification of ceratophryids in semiarid environments. Other embryonic features, such as the morphology and ontogeny of the oral disc and digestive tract, are correlated with larval feeding habits and vary within the family. The evolutionary and ecological significance of some conserved characters (e.g., gastrulation pattern, Type-A adhesive glands) and other taxon-specific features (e.g., nasal appendix) remain to be explored in the group.
\end{abstract}

\section{KEYWORDS}

ancestral reconstruction, sequence heterochrony, transient embryonic structures

\section{1 | INTRODUCTION}

Horned Frogs of the conspicuous anuran family Ceratophryidae include three endemic South American genera. Ceratophrys currently comprises eight species distributed from Colombia and Venezuela to central Argentina and Uruguay (Frost, 2019), whereas the monotypic Chacophrys and three species of Lepidobatrachus are restricted to some areas of Argentina, Bolivia, Brazil, and Paraguay (Faivovich et al., 2014; Frost, 2019). Most ceratophryids inhabit semiarid environments, including xeric areas of the Pacific coasts in Ecuador and Peru
(C. stolzmanni), the Brazilian Caatinga (e.g., C. joazeirensis), and the South American Gran Chaco (C. cranwelli, Chacophrys, and species of Lepidobatrachus). Three species of Ceratophrys develop in humid areas of the Amazon Basin, the Atlantic Forest, and pampean grasslands (C. cornuta, C. aurita, and C. ornata). Morphological and ecological features of larval and adult life are widely variable among ceratophryid genera. Species of Ceratophrys have carnivorous tadpoles that bear a complex oral apparatus with as many as 17 rows of fanglike labial teeth and massive jaw sheaths; the adults are aggressive, predaceous, and carnivorous (Barrio, 1963; Vera Candioti, 2005). Species of 
Lepidobatrachus are unique among anurans in having megalophagous tadpoles with enormous, almost non-keratinized oral discs; the adults are predaceous with behavioral traits resembling those of Ceratophrys (Cei, 1980; Ruibal \& Thomas, 1988). The tadpoles of Chacophrys pierottii are the least modified morphologically and ecologically; they are suspension-feeders with a generalized oral apparatus and metamorphose into predaceous carnivorous adults. However, these larvae are distinguished by having an unusual, autapomorphic nasal appendix (Faivovich \& Carrizo, 1992; Quinzio, Fabrezi, \& Faivovich, 2006). Ceratophryid species share several morphological synapomorphies in their larval and adult body plans. In addition, a suite of heterochronic shifts results in a precocious metamorphosis (sensu Hanken, 1993) that leads to an early acquisition of the characteristic adult phenotypes (Fabrezi \& Quinzio, 2008).

The embryonic ontogeny of ceratophryids and its relationship to the remarkable variation in larval and postmetamorphic biology has not been investigated thoroughly. Ruibal and Thomas (1988) described early stages of Lepidobatrachus laevis and discussed estimated developmental rates. Bloom et al. (2013) studied the initial morphogenesis of the digestive tract in Ceratophrys cranwelli and L. laevis in the context of the evolution of morphological novelties related to changes in feeding ecology. Amin et al. (2015) provided data on growth and organogenesis of $L$. laevis under different temperature regimes and proposed this species as a new model organism for research in developmental biology.

We compared the embryogenesis of Ceratophrys ornata, C. cranwelli, and Chacophrys pierottii highlighting morphological and developmental variation during this period. Observations of young tadpoles of Lepidobatrachus asper are included along with published information on L. laevis in an attempt to frame a discussion of the biology of ceratophryid embryos.

\section{2 | MATERIAL AND METHODS}

We prepared developmental series of the embryos of Ceratophrys cranwelli Barrio, C. ornata (Bell), and Chacophrys pierottii (Vellard), concentrating on the period between the differentiation of the tail bud and the full development of the oral disc. Earlier stages were examined when possible to describe aspects of gastrulation in these poorly known embryos. Ontogenetic series of $C$. cranwelli and Ch. pierottii were obtained from spawn collected in the field during the warm season; embryos were reared in situ under seminatural conditions, with dechlorinated tap water and ambient lighting and temperature. The tadpoles were fed with rabbit food pellets. Four or five embryos were euthanized with lidocaine every 6-12 hr and preserved in buffered formalin. The ontogenetic series of $C$. ornata was obtained after inducing mating by the Amphiplex method (Trudeau et al., 2010), and embryos were raised under controlled laboratory conditions $\left(21^{\circ} \pm\right.$ $1^{\circ} \mathrm{C}, \mathrm{pH}: 7.6-8.3$, hardness: $180-250 \mathrm{mg} \mathrm{CaCO} / \mathrm{L}$, continuous aeration, rearing density of $4.20 \mathrm{~g}$ of tadpole/L). Samples were euthanized every $4 \mathrm{hr}$ and preserved in buffered 10\% formalin. The larvae were fed twice daily with a standardized diet that combined chopped cow liver and fish, live tadpoles, and Tubifex (Salgado Costa, 2016). In addition, we collected and examined five young tadpoles of Lepidobatrachus asper Budgett to compare some developmental events with those of the complete series of the remaining species. We also included developmental series of Boana riojana (Koslowsky) (Hylidae), Odontophrynus americanus (Dúmeril and Bibron) (Odontophrynidae), and material of three leiuperine species (Leptodactylidae) from an earlier contribution (Grosso et al., 2019) to be used as outgroups in the analyses. Data for all specimens examined (including permits for collecting, maintaining and reproducing animals) appear in Supporting Information; Appendix S1.

We studied a total of 332 ceratophryid specimens. A subset of 286 individuals was measured with a Leica M205 stereomicroscope, and 2-16 embryos of each species were dehydrated, critical-point dried, and coated with gold for observation with a scanning electron microscope Zeiss Supra 55VP. We describe the transient embryonic structures (i.e., adhesive and hatching glands, external gills, and epidermal ciliated cells) following the terminology of Nokhbatolfoghahai and Downie (2005, 2007, 2008) and Nokhbatolfoghahai, Downie, Clelland, and Rennison (2005). The larval oral discs and their development were described following terminology of Altig (2007) and Thibaudeau and Altig (1988); the definitive configurations were determined by comparing them with published tadpole descriptions (Cei, 1980; Faivovich \& Carrizo, 1992; Fernández \& Fernández, 1921; Vera Candioti, 2005). Measurements include: body length; proportion of yolk area and dorsal curvature at tailbud stage (the latter was measured in lateral view, as the angle subtended by the embryos body from a dorsal midpoint); length of primary filaments of first and second pairs of gills; average length of secondary filaments of the first two pairs of gills; and average length of all filaments of the third pair of gills.

In addition to structural variations, we explored the diversity of ontogenetic trajectories in terms of three other parameters-viz., size increase, developmental time, and sequence of developmental events. We interpret heterochronic changes under the complementary approaches of growth and sequence heterochrony (Alberch, Gould, Oster, \& Wake, 1979; Smith, 2001). Size and developmental time were represented by total length and number of hours after oviposition, respectively; reliable time data for Ceratophrys cranwelli could not be included. To perform the analysis of sequence heterochrony, a maximum of 24 developmental events were used to construct a summary trajectory for each species. Events are defined as developmental landmarks of embryo morphology and ecology, as follow: (1) differentiation of tail bud; (2) tail length reaching body length; (3) emergence of hind-limb buds; (4) hind-limb length $1 / 2$ its width; (5) division of adhesive glands; (6) regression of adhesive glands; (7) emergence of bud of first pair of gills, (8) emergence of second gill-pair bud; (9) emergence of third gill-pair bud; (10) beginning of the first gill-pair branching; (11) beginning of the second gill-pair branching; (12) differentiation of operculum at gill base; (13) full development of gills; (14) medial fusion of operculum; (15) concealment of right gill; (16) concealment of left gill; (17) differentiation of spiracle; (18) differentiation of oral labia; (19) marginal papillae complete (at least as anlagen); (20) labial tooth 


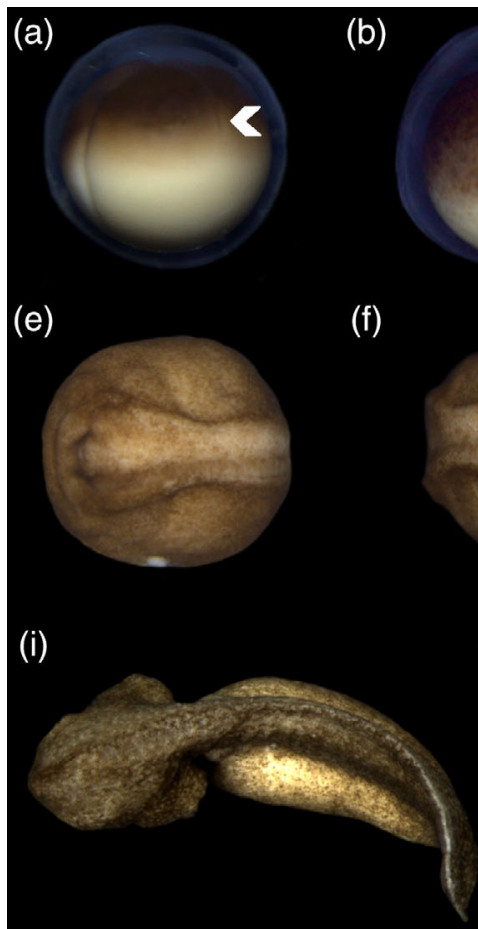

(I)

(j)

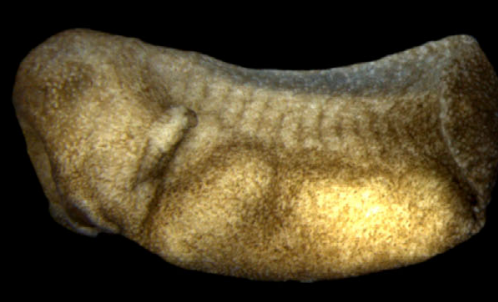

(m)

(n)

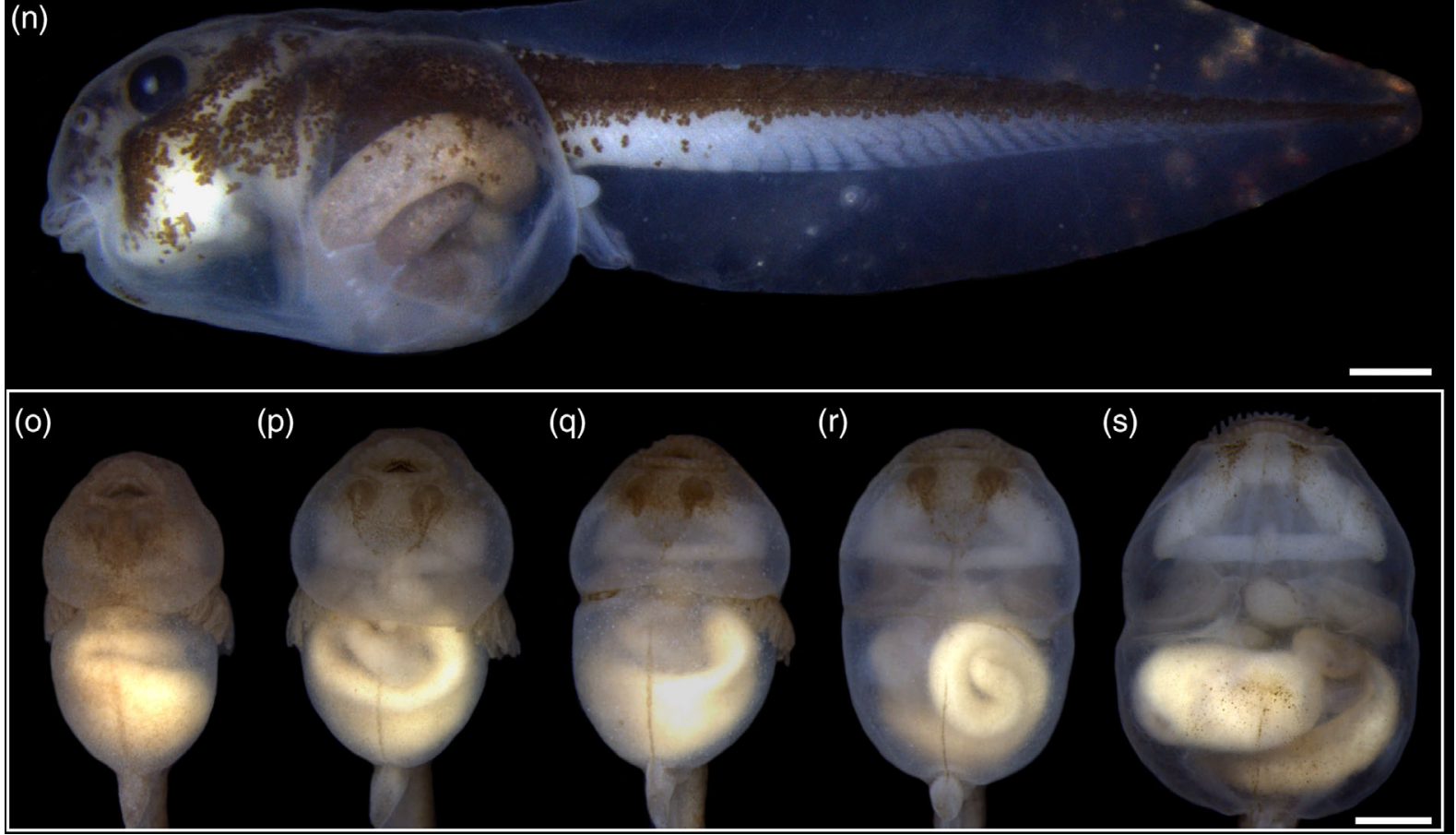

(k)

(h)

(d)

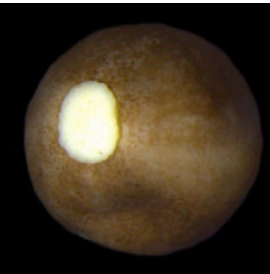

(g)
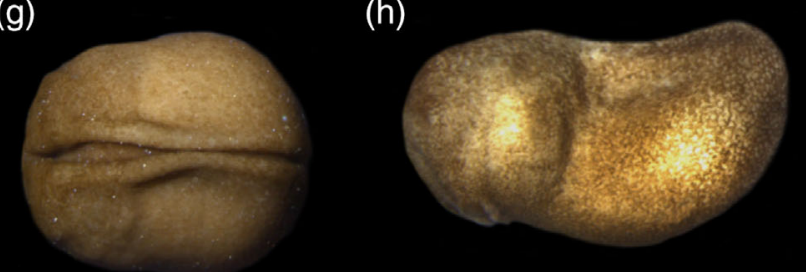

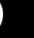
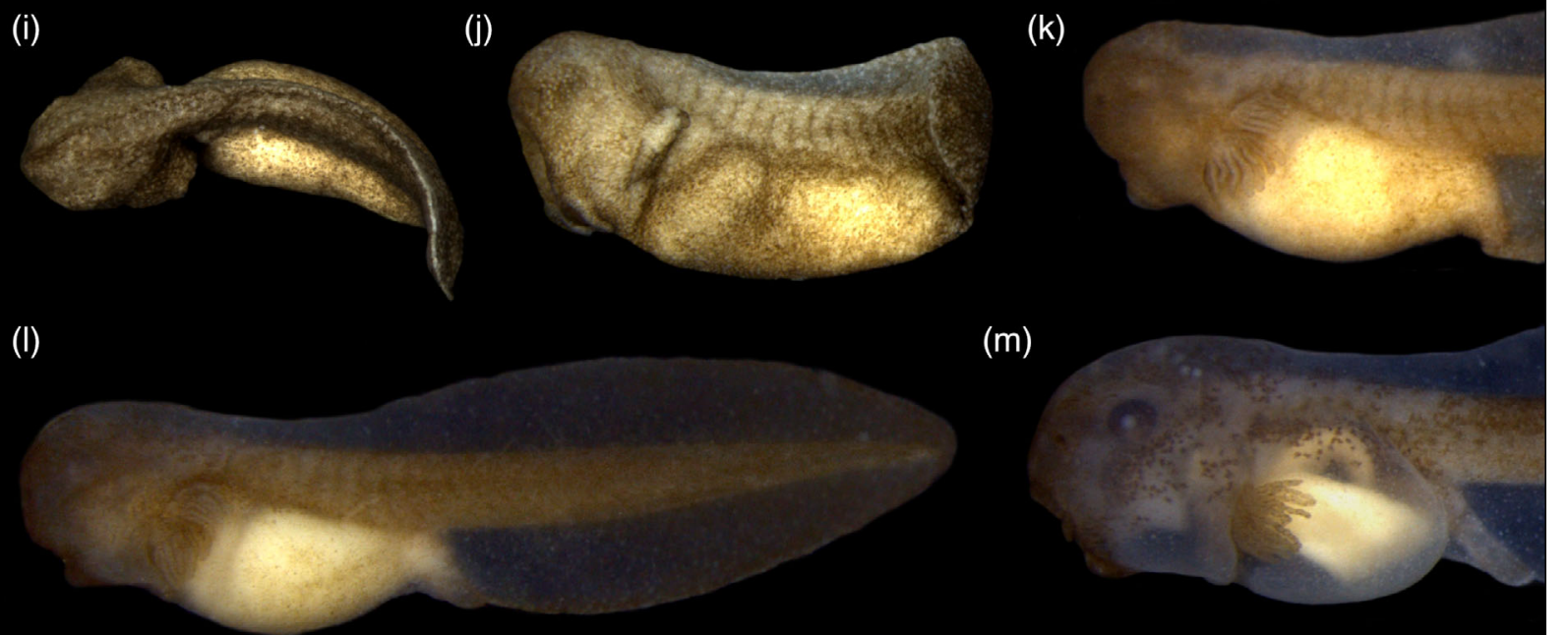

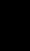




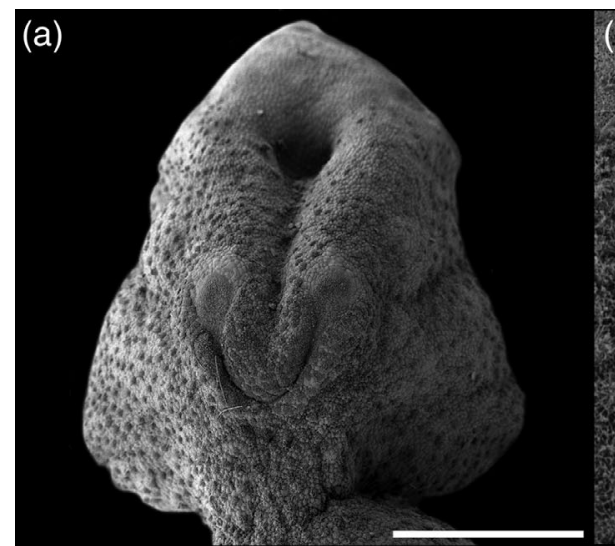

(d)

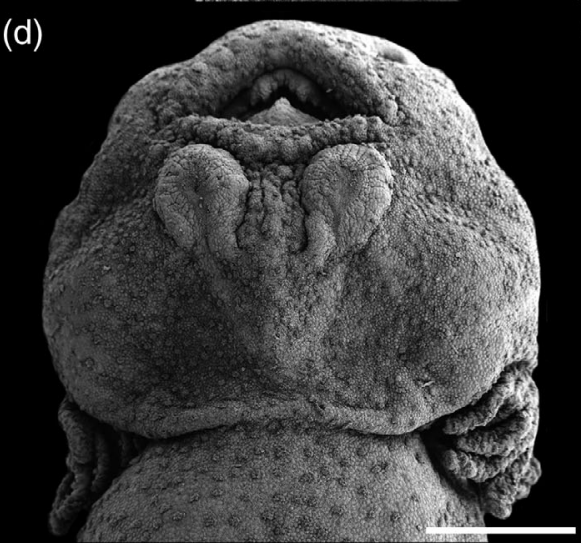

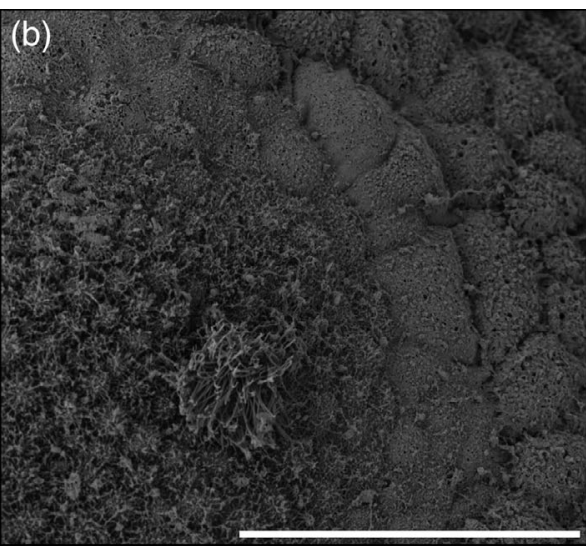

(e)

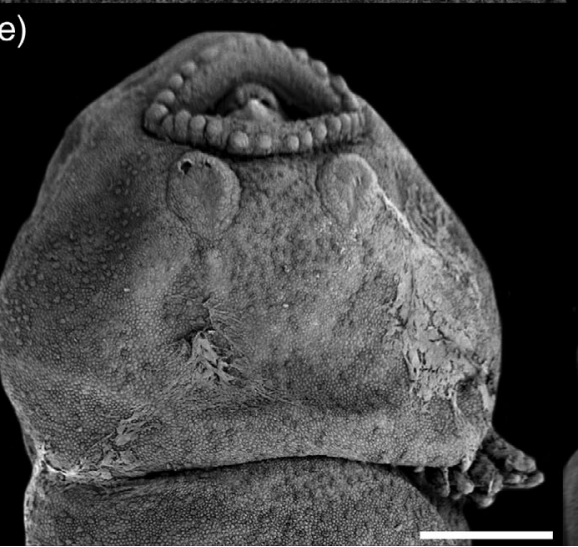

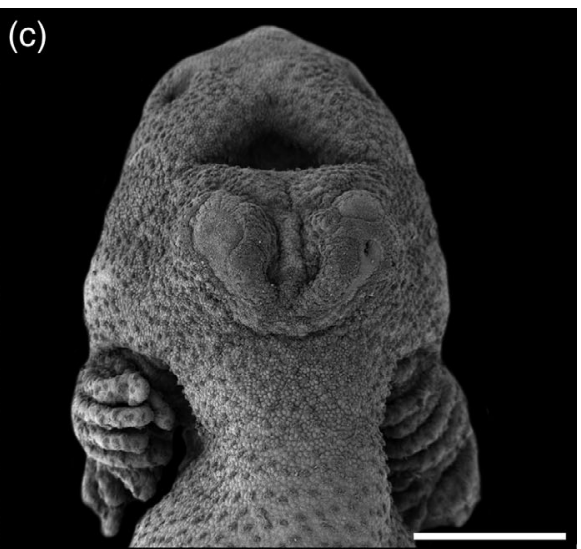

(f)

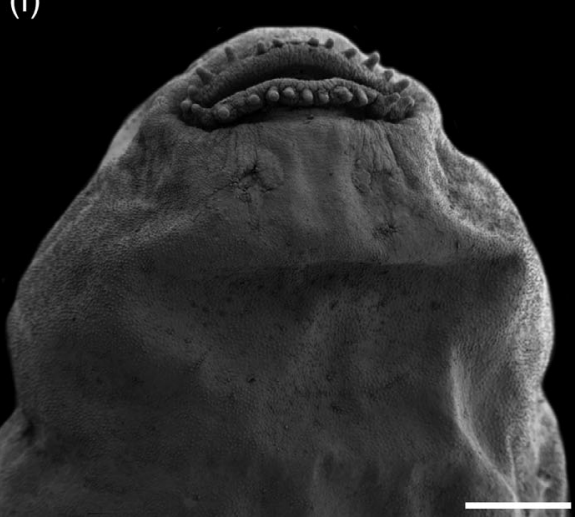

FIGURE 2 Gill and adhesive gland development in Ceratophrys ornata. (a) First gill-pair bud and adhesive gland U-shaped. (b) Detail of the secretory tissue with cells that bear long microvilli. (c) Branched gills and operculum at gill base. (d) Operculum medially fused and adhesive gland in division. (e) Right gill covered by the operculum and separated adhesive glands. (f) Spiracle developed and adhesive glands in regression. Scale bars $=500 \mu \mathrm{m}$ excepting $B=50 \mu \mathrm{m}$. Note the late regression of the glands

row formula complete (at least with labial ridges); (21) emergence of first labial teeth; (22) full development of oral disc (i.e., all mouthparts present at least as anlagen); (23) gastroduodenal loop first visible; (24) onset of active feeding. The moment of hatching was also recorded, but not included in the analyses. Interspecific comparisons were addressed through plots that depict the order at which every event occurs in the complete trajectory, as compared to a reference trajectory (Smith, 2001).

Last, to evaluate heterochronic changes in developmental sequences in a phylogenetic context, we performed a maximum parsimony-based optimization of the ontogenetic sequences on the phylogenetic hypothesis by Pyron (2014). Analyses were made in Rpackage Pgi2 using Parsimov as cost function (Harrison \& Larsson, 2008; Jeffery, Bininda-Emonds, Coates, \& Richardson, 2005), and performing four independent runs each one of 10 trees made with 200 cycles (and 200 replications per cycle). We calculated a pgi super- consensus tree with a tolerance of 50\%-an average of the sequence heterochronies and ancestral sequences recovered in each run calculated with all the trees up to a $50 \%$ difference in tree length.

\section{3 | RESULTS}

A detailed description of the embryonic development of Ceratophrys ornata follows below and is depicted in Figures 1-3. Distinctive features of embryos of $C$. cranwelli are indicated and illustrated in Figure 4. The development of Chacophrys pierottii is summarized next, with distinctive features depicted in Figure 5. Pertinent characters of Lepidobatrachus asper are described and shown in Figure 6. Gosner stages (hereafter GS; Gosner, 1960) are mentioned only when they were determined unequivocally. In cases in which more than one diagnostic event occurs (e.g., initial stages of hind-limb development may

FIGURE 1 Early development in Ceratophrys ornata. (a) Embryo in cleavage, showing the second furrow progressing to the vegetal pole. (b) Early gastrula, with outlined dorsal lip. (c) Mid gastrula. (d) Late gastrula with reduced yolk plug. (e and f) Early neurula in anterodorsal and posterodorsal views. (g) Closing neural folds in dorsal view. (h) Tailbud stage. (i) Two gill buds. (j) First gill-pair branched and operculum at the base of the gills. (k) Three gill-pairs branched. (I) Full gill development. (m) Operculum medially fused, midgut developing and hind limbs emerged. (n) Spiracle developed and hind limbs as long as wide. (o-s) Development of the digestive tract, from GS23 to GS28. Scale bars = $2 \mathrm{~mm}$. Note the blastopore still open in elongated embryos, and the transverse position of the developing stomach during digestive tract differentiation 
overlap with the final stages of gill development in ceratophryids), the stage is labeled according to both events. Raw data for tadpole measurements, developmental stages, and times are presented in Supporting Information, Appendices S2 and S3, and the sequences of developmental events used in sequence heterochrony and ancestral state reconstructions are listed in Supporting Information; Appendix S4. This information is summarized in Figures 7-9, in which size, time, Gosner stages, and sequences of developmental events are plotted comparatively to provide a framework for discussion about heterochronic shifts during development.

\section{1 | Embryonic development of Ceratophrys}

The early development of Ceratophrys ornata from oviposition to GS29 lasts almost 6 days, during which time the size of the embryo increases from $\sim 2 \mathrm{~mm}$ (egg diameter, including capsules $=2.5 \mathrm{~mm}$ ) to $17 \mathrm{~mm}$ (Figure 7). In C. cranwelli, the youngest embryos in our series are at late gastrula stage and are about the same size (Figure 4a;
Supporting Information, Appendix S2); the range examined terminates in GS26-27 and lasts 14 days, with average body length reaching $13 \mathrm{~mm}$ (Figure 7). Eggs of $C$. ornata are surrounded by dense and homogeneous jelly layers; the outermost layer is thick and coriaceous and can be removed easily from the inner layer. Egg pigmentation is concentrated in the animal hemisphere. Eggs undergo a holoblastic cleavage, with vegetal blastomeres larger than animal blastomeres (Figure 1a). Cleavage occurs slower in the vegetal hemisphere. Embryos reach mid-cleavage (GS8) within an hour of fertilization; the beginning of gastrulation is marked by the appearance of the dorsal blastopore lip (GS10) $2 \mathrm{hr}$ later (Figure 1b). The lip of the blastopore expands to have dorsolateral, lateral, and ventral sides, and the yolk plug is formed (Figure 1c). During the late gastrula stage, the diameter of the yolk plug decreases until it completely closes $\sim 5 \mathrm{hr}$ after fertilization (Figure 1d). At neurulation (GS13-14), the embryo elongates while the neural folds begin to form and the blastopore is still open (Figure 1e,g). The future pharyngeal arches are evident. At GS16 (Figure 1g), the neural tube is open, and the ventral adhesive gland is represented by a wide $U$-shaped area; the hatching gland is

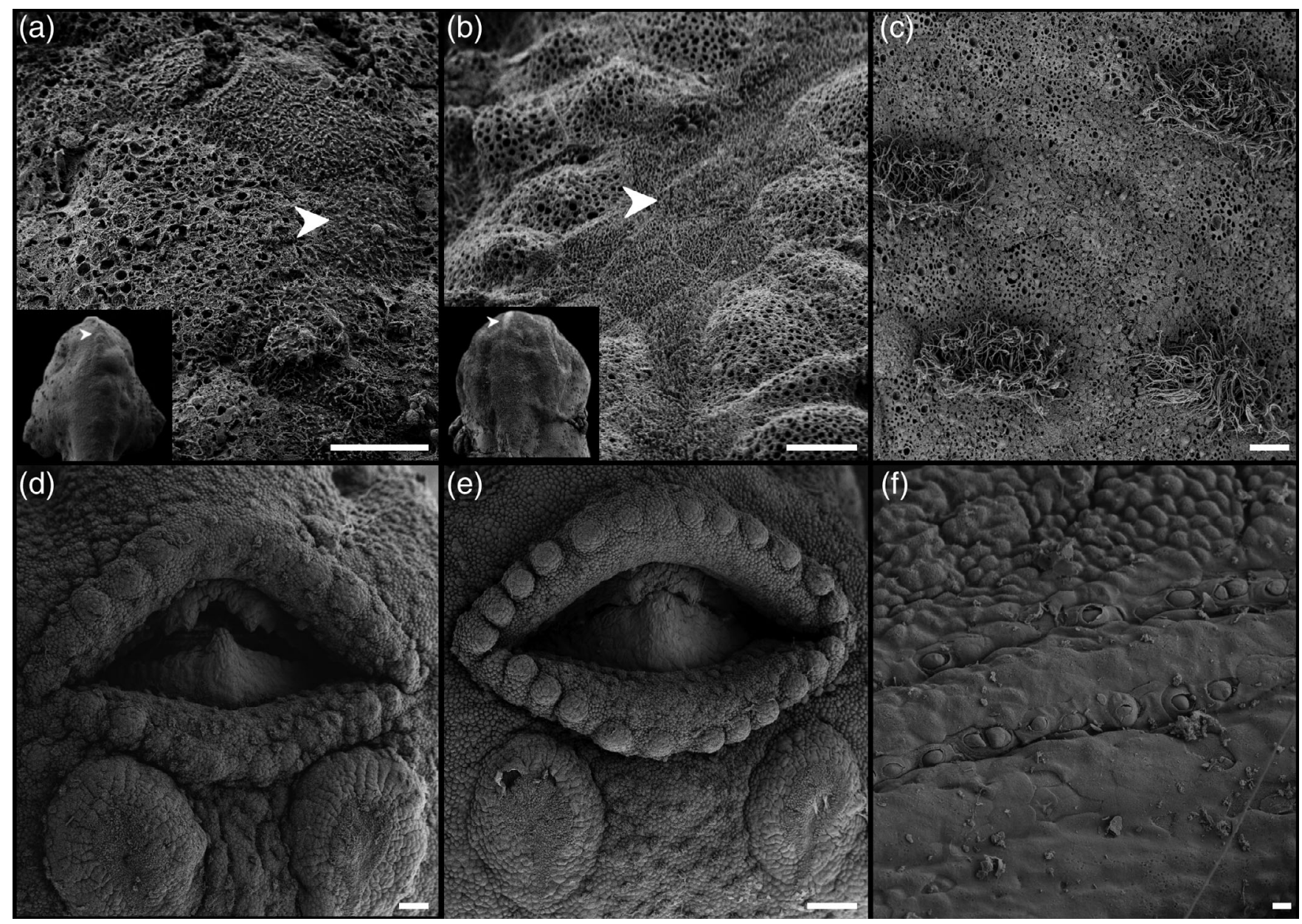

FIGURE 3 Hatching gland, ciliated cells, and oral disc development in Ceratophrys ornata. (a) Hatching cells in the dorsal cephalic region of an embryo with gill buds. (b) Hatching cells in an embryo with regressing gills. (c) Detail of ciliated cells from the abdominal region in an embryo with operculum at gill base. (d) Oral disc with serrated jaw sheaths and marginal papillae outlined. (e) Nearly complete marginal papillae and developing labial ridges. (f) Detail of noncusped labial teeth emerging in upper labial ridges of an older specimen. Scale bars $=10 \mu \mathrm{m}$ excepting $\mathrm{d}$, $\mathrm{e}=100 \mu \mathrm{m}$. Note the delayed regression of hatching gland cells and the early differentiation of jaw sheaths 


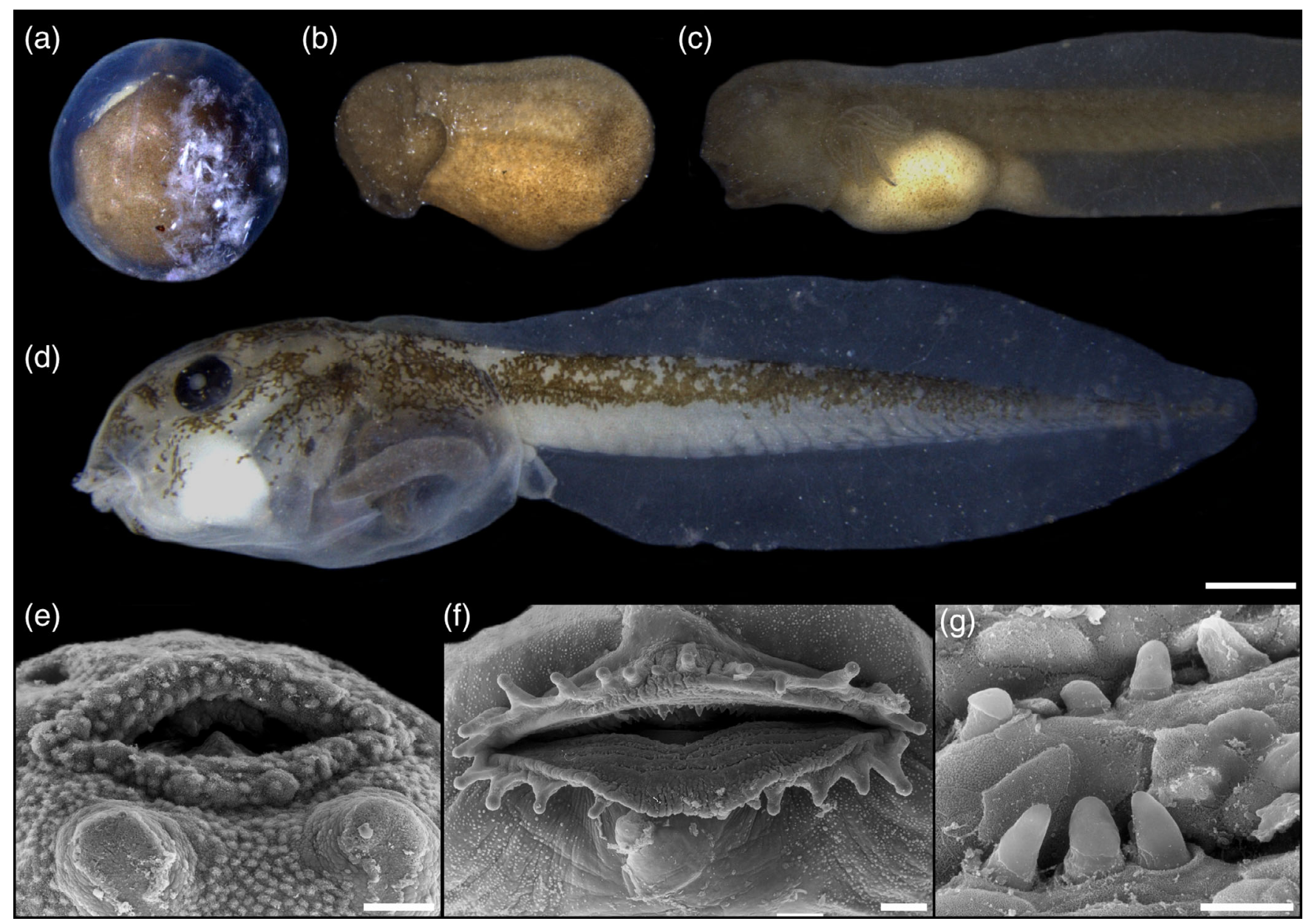

FIGURE 4 Early development of Ceratophrys cranwelli. (a) Mid gastrula. (b) Embryo at tailbud stage. (c) Embryo with fully developed gills. (d) Tadpole at GS26-27. Oral disc development: (e) Serrated jaw sheaths in an embryo with operculum medially fused. (f) Marginal papillae complete and labial tooth row formula <4/4 in a GS27 specimen. (g) Detail of noncusped, spike-like labial teeth in the lower labium. Scale bars $=1 \mathrm{~mm}$ excepting e, $\mathrm{f}=100 \mu \mathrm{m}$, and $\mathrm{g}=10 \mu \mathrm{m}$. Note the almost straight tailbud embryo, and the late differentiation of labial tooth ridges

configured in a short line that is restricted to the most anterior part of the cephalic region. Gill arches appear on each side of the cephalic region $14 \mathrm{hr}$ after fertilization, and hatching cells are arranged in large patches (Figure 3a). Embryos at tailbud stage (GS17; Figure 1h) are light brown; the body is curved slightly away from the yolk (lordotic curvature). Body length increases to about $4 \mathrm{~mm}$ and the oval-shaped yolk represents $\sim 46 \%$ of the body area (Supporting Information; Appendix S3). Tailbud embryos of $C$. cranwelli are similar in size; the body is mostly straight, but the caudal region is slightly curved ventrally (Figure 4b; Supporting Information; Appendix S3). The developing caudal fin is represented by thick ridge in each species. The adhesive gland acquires a $\mathrm{V}$-shaped configuration with a deep groove joining two protruding circular areas with abundant microvillied secretory cells (Figure 2a,b). The hatching gland extends dorsally in a dark zigzag line beyond the gill arches (Figure 1i). Later, the first and second pairs of gills differentiate (Figure 1j). Most embryos of $C$. ornata hatch within the first day after fertilization while the second and third pairs of gills are differentiating. In contrast, embryos of C. cranwelli hatch earlier while the second pair of gills is differentiating. At $26 \mathrm{hr}$, embryos of $C$. ornata develop 5-7 small branches in the first gill pair; the hatching gland becomes T-shaped, and the stomodeum remains closed. Thirty hours after fertilization the operculum covers the gill bases and the second gill pair branches (Figure 1k). In C. cranwelli, the first and second pairs of gills are already branched when the third gill pair differentiates, and the operculum covers the gill bases before the length of the tail equals that of the body. Body ciliation in both species is profuse and ciliated cells are oblong and slightly larger than epidermal cells (Figure 3c). Slightly later in this stage, the oral disc in specimens of $C$. ornata is delimited by a curved upper labium and a smooth lower labium, and the third pair of gills branches; the secretory areas of the adhesive glands grow longer, and the groove connecting becomes shallower (Figure 2c). The body and tail lengths are equal at this stage (Figure 1I). The operculum expands medially, and gills become fully developed before the operculum fuses with the ventromedial body wall (Figures $1 \mathrm{~m}$ and $2 \mathrm{~d}$ ); in the digestive tract, a concavity visible ventrally on the left side of the body marks the union between a short foregut and a longer midgut (Figure 10). Fully developed gills are slightly longer in embryos of $C$. cranwelli than in 

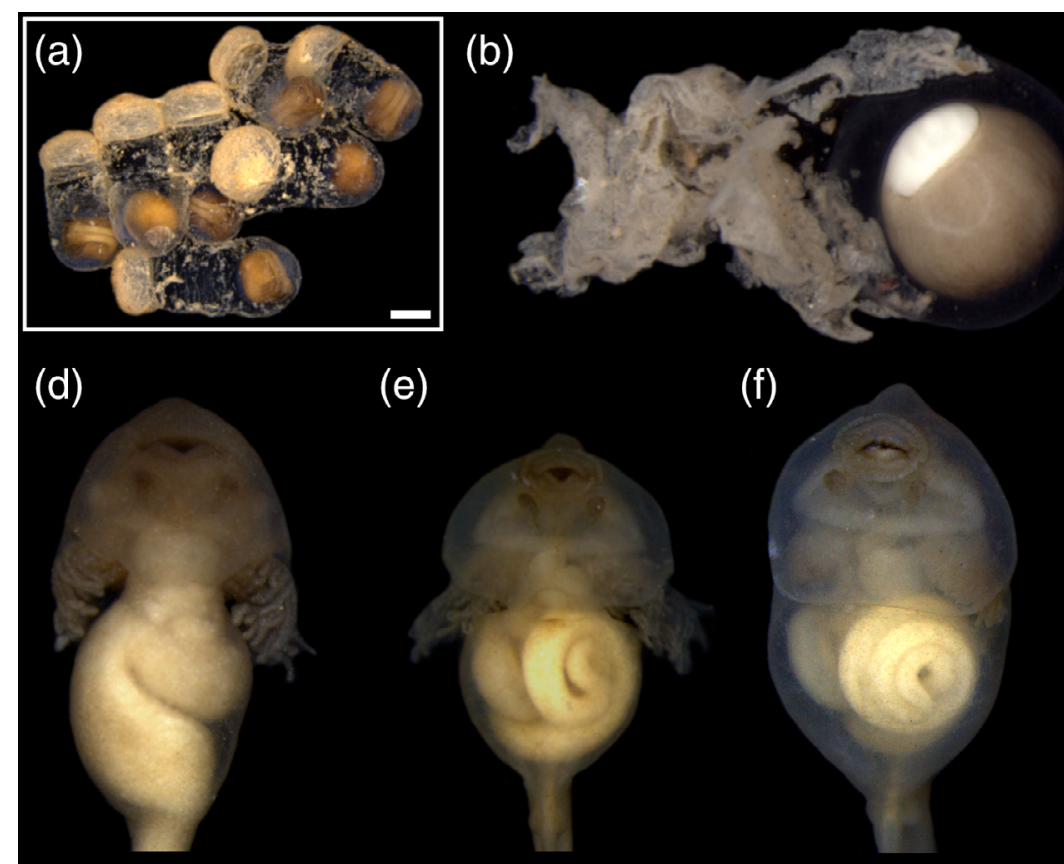

(e)

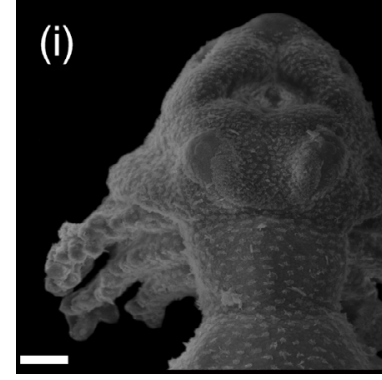

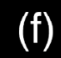

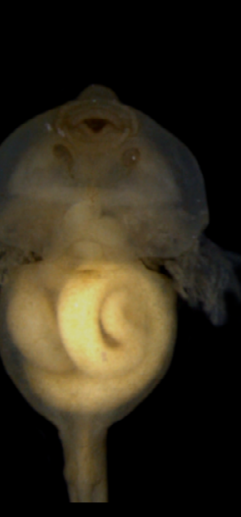

(f)

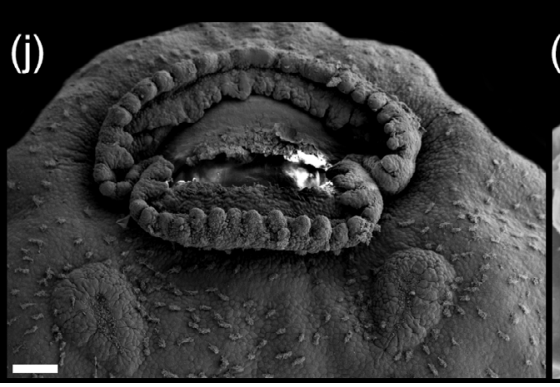

(c)

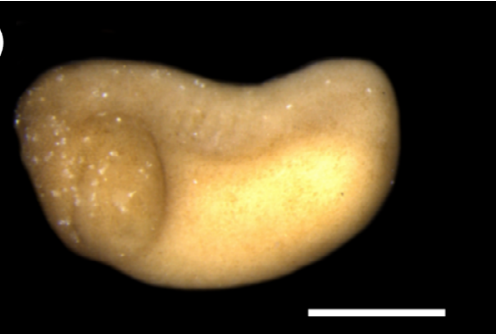

(h) (g)

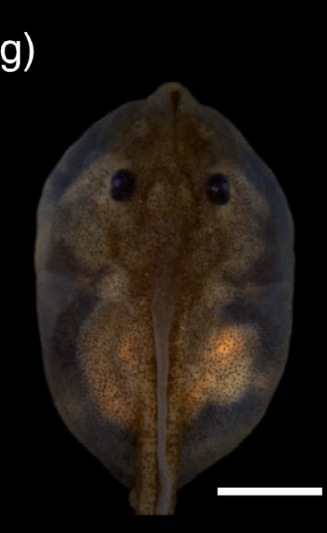

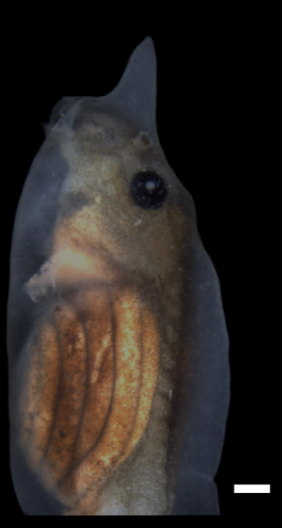

FIGURE 5 Early development of Chacophrys pierottii. (a) Stalked eggs. (b) Mid gastrula out of the coriaceous egg capsule. (c) Embryo at tailbud stage. (d) Embryo with fully developed gills. (e) Embryo with emerged hind limbs and operculum medially fused. (f) Embryo with the right gill concealed and hind limbs at GS27. (g) Embryo with spiracle developed. (h) Detail of the nasal appendix of a GS30 wild tadpole. Details of the oral disc and adhesive gland development: (i) Adhesive gland during division. (j) Adhesive glands separated and nearly complete oral disc in a GS25/28 embryo. (k) Oral disc in a >GS28 tadpole; inset shows an individual labial tooth from first upper row. Scale bars $=1 \mathrm{~mm}(\mathrm{a}-\mathrm{h})$ and $100 \mu \mathrm{m}$ (i-k). Note the generalized digestive tract and the early differentiation of the nasal appendix

C. ornata (Figure 4c; Supporting Information; Appendix S3). Neuromasts of the preopercular, angular, and infraorbital lines are evident in both species. The developing larval stomach is oriented transversely (Figure 1p). Forty-two hours after fertilization, the jaw sheaths develop in the oral disc of $C$. ornata, and the caniniform and spike-like projections typical of the larval upper and lower sheaths are evident; the first commissural papillae appear and further papillation develops in a lateral-to-medial direction (Figures 3d,e). Oral disc development in C. cranwelli follows a similar pattern (Figure 4e). The separate adhesive glands are connected medially by a dark pigmented line without secretory cells (Figure $2 \mathrm{~d}$ ). The prospective larval stomach occupies the lower half of the abdominal region and hind-limb buds emerge on each side of the tail base (Figure 1q). Hatching cells are still evident (Figure 3b). Marginal papillae are present around the perimeter of the oral disc; the labial ridges begin to differentiate (Figure 3e) and the active feeding begins-earlier than in C. cranwelli. At the same time, the operculum conceals the right gill (Figure 2e). About 3 days after fertilization, the left gill is covered by the operculum and the hind limbs are free from the body and lengthen to become half their width. In C. cranwelli, when the left gill pair is covered by the operculum, the hind-limb buds appear, marginal papillae are present at the perimeter of the oral disc, and the jaw sheaths develop serrated margins. The short midgut is coiled in the left side of the abdomen (Figure 1r). The spiracle develops during the fourth day of the development of C. ornata (Figure 1n). At this stage, marginal papillae are longer and the amount of body ciliation abruptly decreases. The adhesive glands are greatly reduced and not protuberant (Figure $2 \mathrm{f}$ ). The digestive tract shows its larval arrangement (Figure 1s). In C. ornata, additional labial ridges differentiate in the oral disc during the fifth day; they are low and smooth, and form in a proximal direction. Labial teeth emerge at almost the same time that the ridges develop; the lower labium differentiates faster than the upper labium (Figure 3f). The final configuration of the oral disc is completed later during larval life. Marginal papillae become longer as the embryos grow, and spike-like labial teeth emerge in labial ridges. The larval labial tooth row formula in C. ornata (up to 8/8) is acquired after GS29, and GS26-27 tadpoles of 


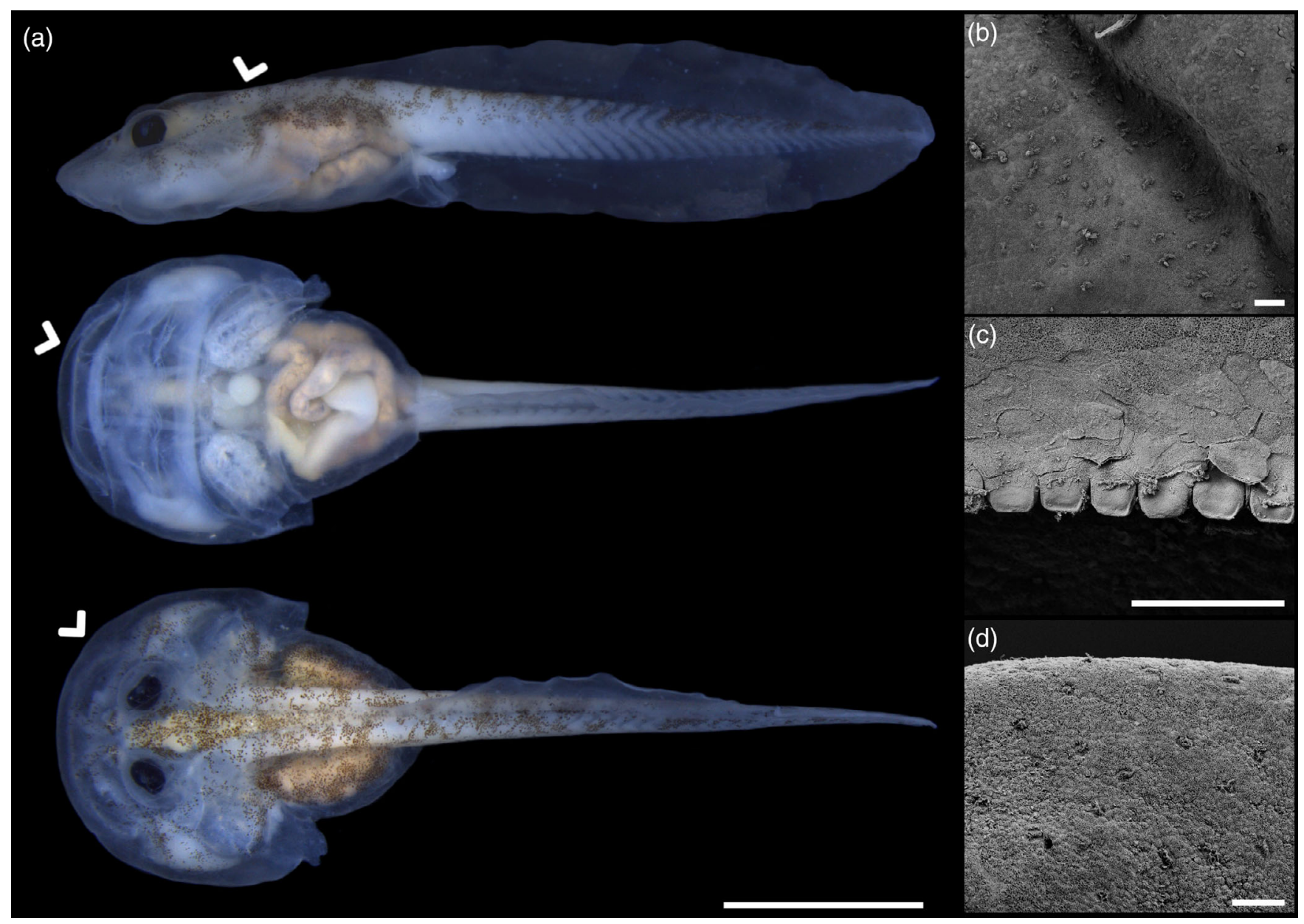

FIGURE 6 Early tadpoles of Lepidobatrachus asper. (a) Tadpole at GS31 in lateral, ventral, and dorsal views. (b) Ciliated cells from the dorsal body. (c) Detail of the upper jaw sheath. (d) Supralabial neuromasts on the upper lip. Scale bars $=5 \mathrm{~mm}$ (a) and $50 \mu \mathrm{m}$ (b-d). Arrows show the place where image details are selected. Note the transverse arrangement of the larval stomach and the short midgut

C. cranwelli (the oldest in our sample; Figure $4 \mathrm{f}, \mathrm{g}$ ) still have an incomplete LTRF (6/6 instead of the usual formula of 8/8).

\section{2 | Embryonic development in Chacophrys pierottii}

The sequence sampled includes GS1-29 within a period of $82 \mathrm{hr}$ (Figure 7). At neurulation, the outermost egg capsule is pear-shaped, wrinkled, and thick at one extreme and smoother and thinner at the other where the spherical inner jelly layers containing the embryo are housed (Figure $5 \mathrm{a}, \mathrm{b}$ ). At the beginning of the neurulation, the embryo elongates, and the neural folds start to form while the blastopore remains open. Tailbud embryos are light brown, highly ciliated, and have a pronounced lordotic curvature (Figure 5c). Embryos are smaller than those of Ceratophrys but have a similar yolk proportion $(\sim 3 \mathrm{~mm}$ and 42\%; Supporting Information; Appendix S3). Developmental sequences correlated with data on developmental time enable meaningful comparisons of Chacophrys and Ceratophrys (Figure 8a,b). The external gills, along with the hatching and adhesive glands, are morphologically and ontogenetically similar among genera
(Figure 5d-f); likewise, the hind limbs emerge early in the whole developmental sequence. Body ciliation persists in several areas until GS29. The main differences involve morphogenesis of the digestive tract, and the timing of adhesive gland and gill development. The onset of gut development precedes the medial fusion of the operculum (Figure $5 \mathrm{~d}$ ). The foregut is arranged on the right of the abdominal region, and the longer midgut is coiled on the left (Figure $5 e, f$ ). Division of the adhesive glands occurs earlier in the sequence (long before the right gill is covered by the operculum) and slightly earlier in absolute time; this likely allows for an earlier development of the oral line of neuromasts as contrasted to Ceratophrys. Regression of adhesive glands is delayed relative to other events. In addition, in embryos of Chacophrys, gill and spiracle development seem to be delayed in the sequence, but absolute time data show that the complete cycle from gill branching to spiracle differentiation takes less time than in Ceratophrys. The ontogeny of the oral disc in Chacophrys and Ceratophrys also differs (Figure 5i-k). The larval oral apparatus of $\mathrm{Ch}$. pierottii has the usual morphology of two upper and three lower labial tooth ridges. Labia differentiate after the three pairs of gills have branched and the jaw sheaths differentiated. Tooth rows develop in a sequence common to other tadpoles, that is, rows $\mathrm{A} 1$ and P2 followed by 
FIGURE 7 Growth heterochrony in ceratophryid embryos. (a) Size increase during Gosner stage progression. (b) Size increase during developmental time. Developmental times for Ceratophrys cranwelli are not available, and data for Lepidobatrachus laevis are reproduced from published information (Amin et al., 2015; Ruibal \& Thomas, 1988).

Odontophrynus americanus early development is shown for comparative purposes. Curves depict the ontogenetic period between GS1 (except for C. cranwelli data that start at GS11) and GS25/26-27 (C. cranwelli and L. laevis) or GS29 (C. ornata and Chacophrys pierottii). Raw data (dots) are listed in Supporting Information, Appendix S2, and lines of tendency are adjusted by a local polynomial regression (LOESS; R-package ggplot2); light shades along curves are 95\% confidence intervals from bootstrapped regression residuals. Dots at the upper right show values for GS33 tadpoles taken from literature; field data were considered in order to represent more accurately larval size/developmental time (Do Nascimento, Mott, Langone, Davis, \& de Sá, 2013; Fabrezi et al., 2016; Natale et al., 2011). In panel (a), curves oversimplify the fact that Gosner stages are not a continuous variable, and they are particularly artificial in ceratophryids where gill-based stages and hind limbbased stages partially overlap. The dotted vertical line indicates external gills fully absent (defining GS25), and the black arrows point out the stages (still gilled in ceratophryids) where hind limbs emerge (GS26). Note the smaller size in Chacophrys embryos and the cooccurrence of gills and hind limbs in ceratophryids (a) 50

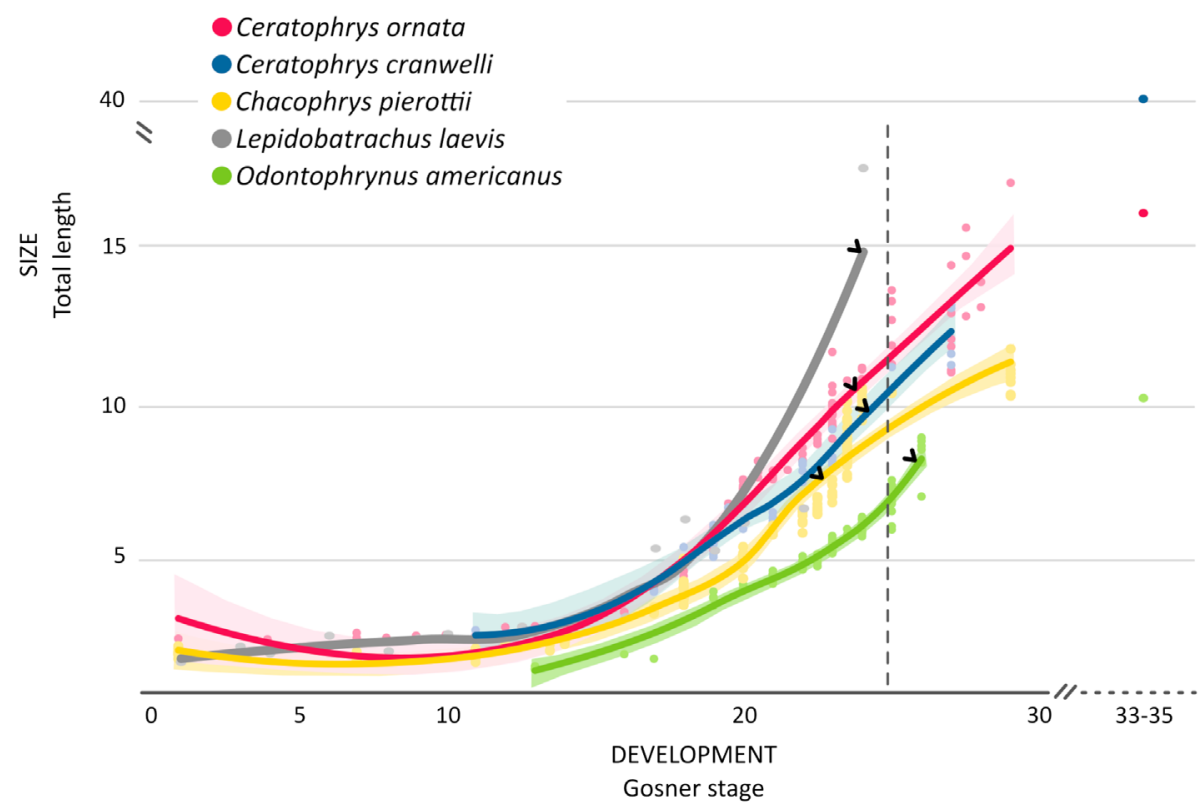

(b) 50

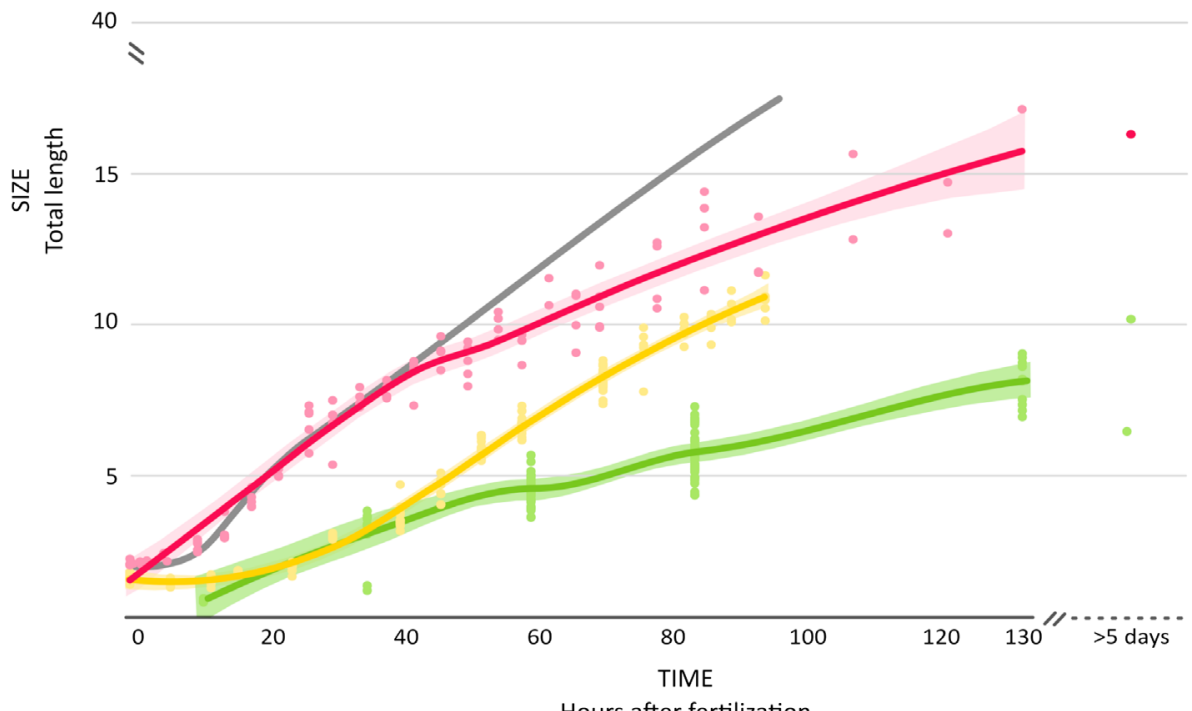

divided rows $\mathrm{A} 2$ and $\mathrm{P} 1$, and finally a shorter P3; the serrated margins of jaw sheaths develop after all tooth ridges are outlined. Marginal papillae develop medially from commissures, and the middorsal region is the last to complete development; this occurs later than in larvae of Ceratophrys. On the lower labium, papillae may appear alternately (as evidenced by uneven-sized papillae with wide gaps in some specimens); this alternate configuration remains in lower papillae of older tadpoles. The first labial teeth emerge on row $\mathrm{P} 2, \mathrm{~A} 1$, and later in the remaining labial ridges. Labial tooth shape is similar, but minute cusps appear in teeth of some specimens (Figure 5k). As in Ceratophrys, the lower labium seems to develop slightly more rapidly; in contrast, the larval oral configuration co-occurs with total regression of the adhesive glands much earlier in time. Finally, the peculiar nasal appendix begins to differentiate when the gills are fully developed and grows to reach its full length (6.5\% body length) at GS29 (Figure $5 \mathrm{~g}$ ). The dark dorsal line associated with the hatching gland in young embryos persists in these "nosed" specimens but hatching-gland cells are absent. Older specimens of the same series lack the appendix, but in a lot collected in the field, all tadpoles, including older individuals at GS38-39, have long appendices (Figure 5h).

\section{3 | Young tadpoles of Lepidobatrachus asper}

Given the lack of material, our observations of larvae of Lepidobatrachus asper are limited. In GS31 tadpoles (Figure 6a) body 


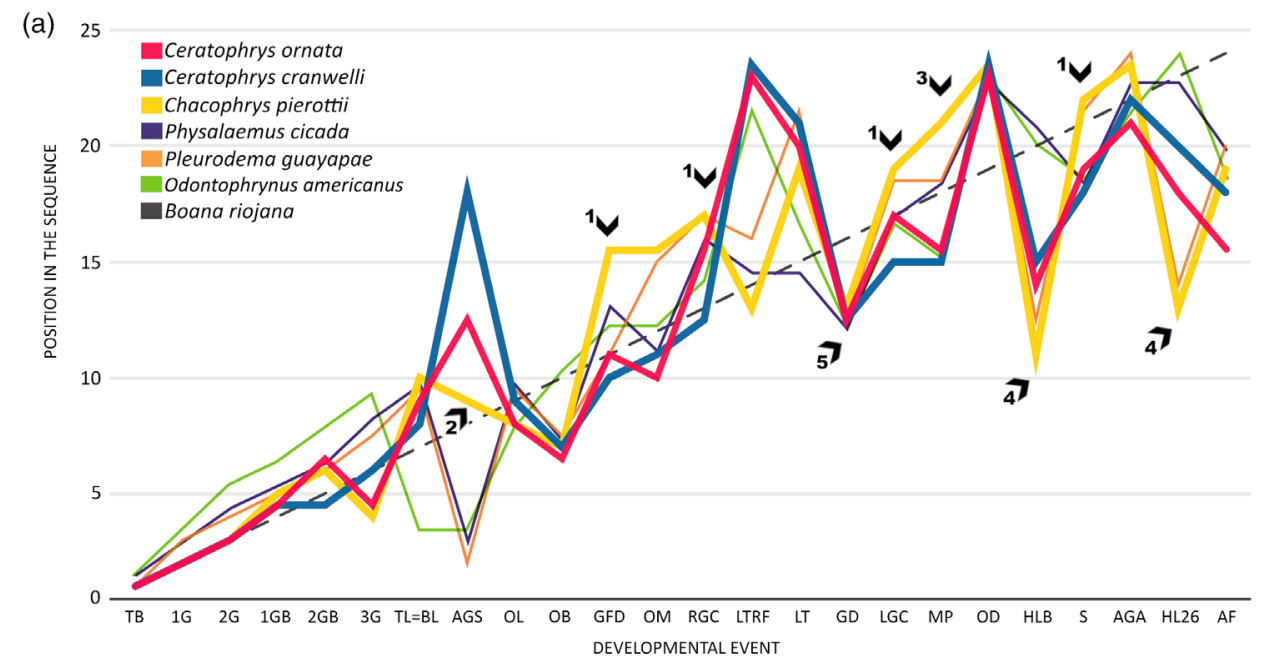

(b)

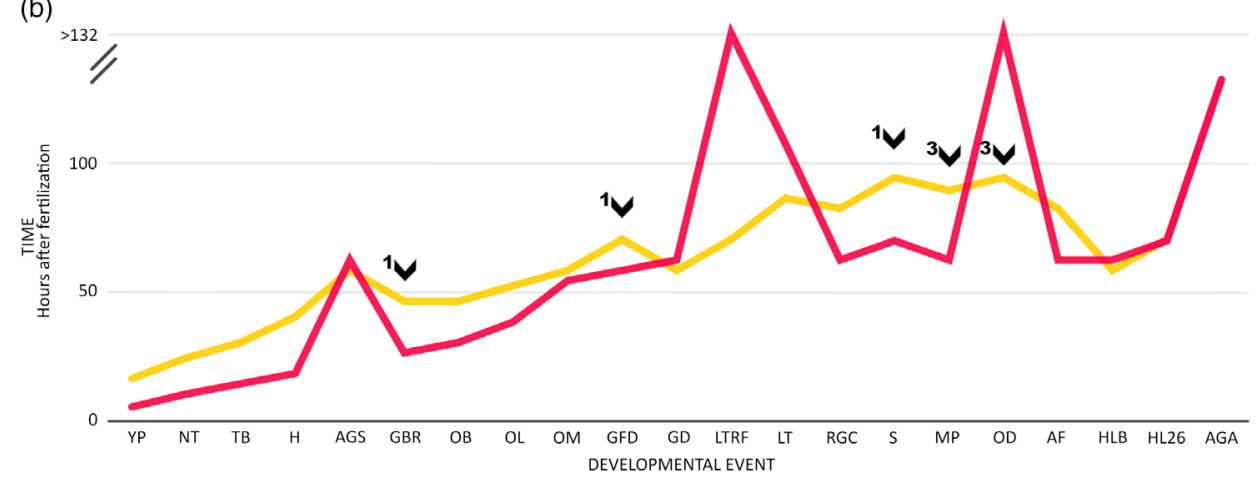

FIGURE 8 Sequence heterochrony in ceratophryids. (a) Sequence heterochrony plot showing the order in the sequence at which each developmental event occurs. (b) Absolute times at which landmark developmental events occur. Developmental times for Ceratophrys cranwelli are not available. Reference trajectory in the event/order plot is Boana riojana, and we also show data of related Odontophrynus americanus, and two leiuperine embryos from dry environments to highlight some ecological convergences. Raw data of these plots are listed in Supporting Information, Appendix S4. AF, onset of active feeding; AGA, adhesive glands absent; AGS, adhesive glands separated; GD, gastroduodenal loop first visible; GFD, full gill development; HLB, hind-limb bud; HL26, hind limb $\frac{1}{2}$ longer than wide; LGC, left gill covered; LT, first labial teeth; LTRF, labial tooth row formula complete; MP, marginal papillae complete; OB, operculum at gill base; OD, larval oral disc complete; OL, labia differentiated in the oral disc; OM, operculum medially fused; RGC, right gill covered; S, spiracle developed; TB, tail bud; TL=BL tail reaching body length; 1G, first gill-pair bud; 1GB, first gill-pair branching; 2G, second gill-pair bud; 2GB, second gill-pair branching; 3G, third gill-pair bud. Further or simplified events in (b) are AG, adhesive gland first visible; GBR, gill branching; $\mathrm{H}$, hatching; NT, neural tube; YP, yolk plug. Arrows show main heterochronic shifts commented in text: 1 delayed gill events and 2 early division of adhesive glands in Chacophrys; 3 delayed marginal papillae plus precocious acquisition of larval oral disc in Chacophrys; 4 early hind-limb differentiation; and 5 early digestive tract coiling in all ceratophryid species

ciliation is present, especially dorsally (Figure 6b). Adhesive and hatching glands are absent, and the upper and lower jaw sheaths are keratinized (Figure 6c). The supralabial neuromasts (an extension of the angular line to the upper lip, a synapomorphy of Lepidobatrachus; Fabrezi \& Quinzio, 2008; Quinzio \& Fabrezi, 2014) are evident in this stage (Figure 6d).

\subsection{Reconstruction of ancestral ontogenetic sequences}

We found phylogenetically informative shifts in the relative timing of developmental events involving the oral disc, gills, adhesive glands, gut, and proportions of the hind limbs and body. The optimization of developmental sequences on the reference phylogeny resulted in a super-consensus tree with 38 heterochronic movements. The original trees were searched in blocks of 10 runs and resulted in trees ranging in length from 54-59. The events having the most shifts involve the development of oral disc (LTRF, MP), onset of active feeding, division of adhesive glands, and differentiation of hind limbs (HLB, HL26). In contrast, events describing initial steps of gill development (1G, 2G, $1 G B)$, tail-bud differentiation, medial fusion of the operculum with the body wall, and regression of adhesive glands are consistent in their positions in the sequences of the consensus tree. Three shifts are recovered as heterochronic synapomorphies of Ceratophryidae-viz., accelerated (1) emergence and (2) development of hind limbs; and (3) delayed lengthening of the tail (Figure 9). Three heterochronic events define Ceratophrys-(1) early differentiation of marginal papillae; (2) deceleration of adhesive gland division; and (3) deceleration of emergence of the labial teeth. In Chacophrys, hind-limb development 


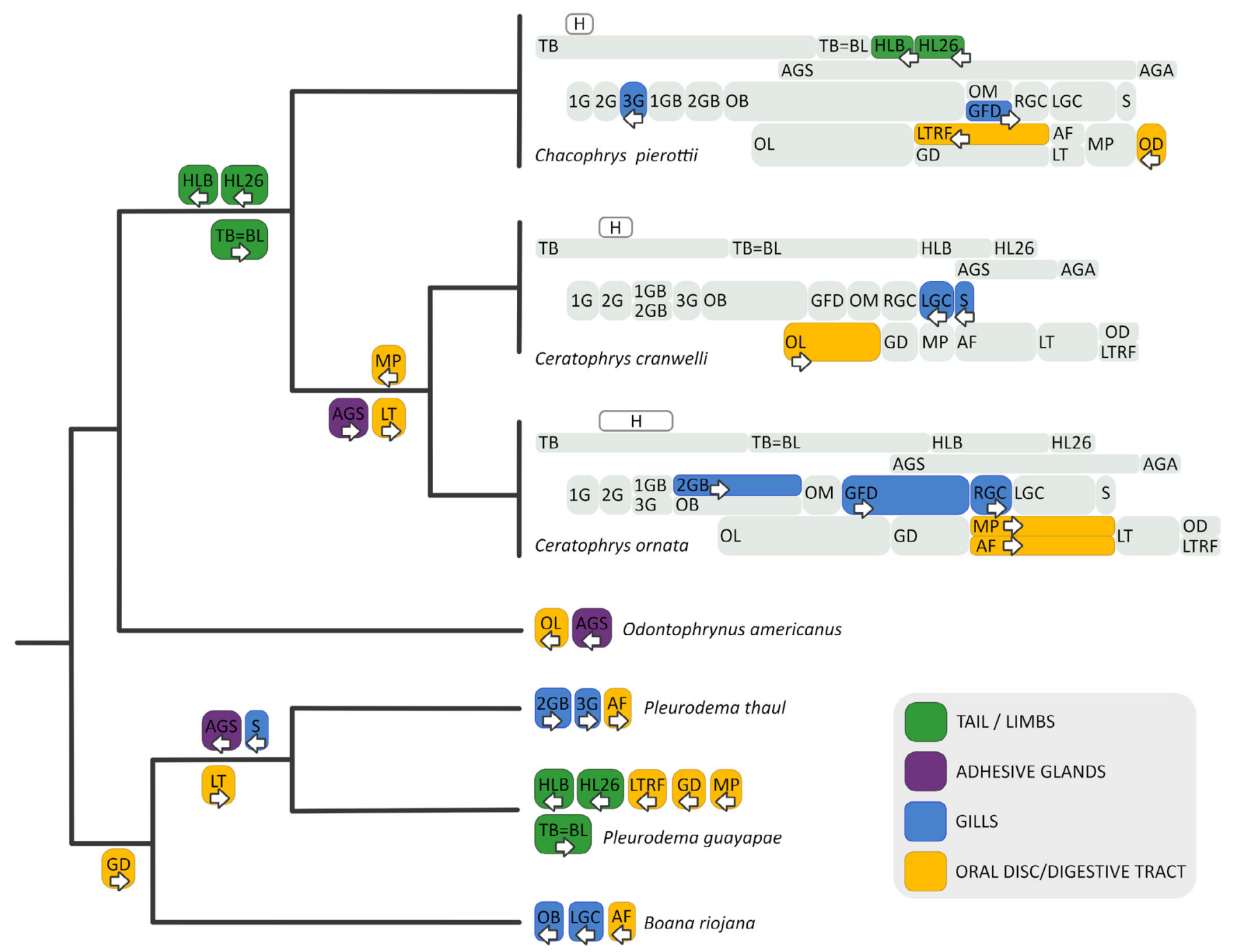

FIGURE 9 Ancestral state reconstruction of developmental trajectories in ceratophryids. The phylogenetic hypothesis by Pyron (2014) is used as reference. Raw data with developmental sequences are listed in Supporting Information, Appendix S4. Schemes in grey show the full event sequences for ceratophryids: rows summarize the ontogeny of a set of traits (from top to bottom tail/hind limbs, adhesive glands, gills, and oral disc/digestive tract), and hatching is indicated in the topmost row (h); events aligned in columns occur synchronically. Synapomorphic heterochronic shifts are highlighted, colored according to the trait considered, and showing the direction of shifts through arrows (pointing left arrows as early occurrences, pointing right arrows as delayed occurrences). AF, onset of active feeding; AGA, adhesive glands absent; AGS, adhesive glands separated; GD, gastroduodenal loop first visible; GFD, full gill development; HLB, hind-limb bud; HL26, hind limb $1 / 4$ wider than long; LGC, left gill covered; LT, first labial teeth; LTRF, labial tooth row formula complete; MP, marginal papillae complete; OB, operculum at gill base; OD, larval oral disc complete; OL, labia differentiated in the oral disc; OM, operculum medially fused; RGC, right gill covered; S, spiracle developed; TB, tail bud; TLBL tail reaching body length; $1 \mathrm{G}$, first gill-pair bud; $1 \mathrm{~GB}$, first gill-pair branching; 2G, second gill-pair bud; 2GB, second gill-pair branching; 3G, third gill-pair bud. Note the heterochronic shifts in the most recent common ancestor of Ceratophryidae, and the convergences with embryos of Chacoan Pleurodema guayapae

is further accelerated, and differentiation of the third pair of gills and acquisition of all labial ridges and the larval oral disc occurs also early in the sequence; conversely, full development of the gills is delayed.

\section{DISCUSSION}

Ceratophryid species constitute a well-defined monophyletic group characterized by several morphological synapomorphies of tadpoles and adults (Fabrezi \& Quinzio, 2008; Faivovich et al., 2014). Larval synapomorphies include possession of marginal papillae around the perimeter of the oral disc and a cylindrical anal tube; these features occur in all species regardless of their variant premetamorphic morphology and ecology. The adults share several skeletal characters associated with terrestrial and fossorial habits, and the ability to feed on extremely large prey (Fabrezi, 2006; Fabrezi et al., 2016). In embryos, we identified distinct morphological and developmental features that might be synapomorphies of ceratophryids. Early embryos of Chacophrys and Ceratophrys are moderate to large in size; they have light pigmentation and a slight lordotic curvature. Type-A adhesive glands persist long in larval life. The three pairs of gills are long and branched, and body ciliation is profuse and persistent. Hatching 
occurs early in ontogeny of all species, but hatching cells are still evident several stages after embryos hatch. Hind limbs and the digestive tract develop precociously, and tail lengthening is delayed relative to other features. Embryonic development is rapid; embryos reach feeding stages in 2-3 days and increasing their body size by a factor of 6-8 times. The results of Amin et al. (2015) showed that embryos of Lepidobatrachus laevis share some features with Ceratophrys and Chacophrys; among these are color and shape at tailbud stage, morphology of adhesive glands, number of external gills, early hatching, and an abbreviated larval development. However, young embryos of Lepidobatrachus are larger and have more yolk, and growth and development are faster than in other ceratophryids. In captivity, embryos of Lepidobatrachus start to feed before 2 days post-fertilization, and body length during pre-feeding stages is comparatively large (Figure 7). When reared at the extreme of their thermotolerance range $\left(37^{\circ} \mathrm{C}\right)$, growth rate increases extraordinarily and embryos can feed actively during the first day of development. In contrast, tadpoles of the related genus Odontophrynus reach feeding stages 4 days after fertilization and increase 5-6 times in size. Although tentative because of differences in data collection discussed below, our results suggest that growth curves in ceratophryid embryos (Figure 7) differ somewhat from the growth curves reported by Fabrezi et al. (2016) for older larval stages. The latter authors reported that the growth curves of species of Chacophrys and Lepidobatrachus resemble one other closely; each has larger and more advanced (in terms of developmental events) tadpoles than those of Ceratophrys at the same developmental time. Instead, we found that at comparable stages and ages, Chacophrys embryos are the smallest.

Some embryonic features of ceratophryid frogs described here have been discussed in the context of development in bodies of water in xeric environments, which tend to be unstable, warm, and poorly oxygenated. For example, long, branched gills and profuse, longlasting ciliation are convergent characters of some foam-nest leiuperine embryos that inhabit brackish ponds of the South American Chaco and the Brazilian Caatinga (Grosso et al., 2019). Embryos of the Spadefoot toad, Spea intermontana, also remain highly ciliated after gill regression (Hall, Larsen Jr, \& Fitzner, 1997). The risk of desiccation in semiarid areas may impose strong environmental constraints on embryonic and larval development in the water, thereby favoring early hatching and short development (Grainger, 1959; Zweifel, 1968). In this context, an early emergence of hind limbs could be interpreted as a landmark event integrated in a set of heterochronic shifts tending to reduce the larval period and produce a precocious metamorphosis (Fabrezi \& Quinzio, 2008). The early onset of gut coiling and active feeding, and the regression of the anal tube predisplaced to prometamorphic larval stages (Fabrezi \& Quinzio, 2008) also are consistent with this. As in ceratophryids, hind-limb differentiation and the onset of active feeding occur early in the developmental trajectories of scaphiopodids (Buchholz \& Hayes, 2002; Hall et al., 1997) and leiuperines from dry areas (Figure 8; Grosso et al., 2019). Developmental acceleration is achieved by the synergy of increasing levels of corticosterone and thyroid hormones on target tissues such as the limbs and gut (e.g., Wen et al., 2017). An early activation of thyroid and interrenal axes under conditions of pond desiccation was shown experimentally in Spea hammondii (Denver, 1998). In ceratophryids, Fabrezi and Cruz (2014) found low activity in the thyroid gland and suggested that the ability of these species to grow and develop rapidly could be explained by the accumulation of maternal $T_{3}$ and $T_{4}$, an unusual proliferation of heterotopic follicles, and the acquisition of extra exogenous hormones from diet.

Alternate interpretations challenge the hypothesis of an unequivocal relationship between arid environments and a short development to metamorphosis. In pelobatoid species, Buchholz and Hayes (2002) and Zeng, Gomez-Mestre, and Wiens (2014) found that short larval periods and early hatching times are not significantly related to breeding in dry climates, but to small genome sizes and phylogeny. However, the authors specified that a strong relation might exist at the level of populations, or with respect to the presence of larvae in ephemeral versus permanent ponds. In ceratophryids this kind of data is scarce, and values of larval development duration may differ between field and controlled conditions. The shortest time to metamorphosis is 15-18 days in Chacophrys pierottii and species of Lepidobatrachus (field data; Fabrezi et al., 2016). In Ceratophrys, values range from 20-24 days in wild $C$. cranwelli to 25-32 days in C. stolzmanni (Fabrezi et al., 2016; Ortiz, Almeida-Reinoso, \& Coloma, 2013) and 70 days in C. aurita (Miranda-Ribeiro, 1923); in C. ornata, periods from 20 to 32-36 days have been reported (Honegger, Schneider, \& Zimmermann, 1985; Natale et al., 2011). Faivovich et al. (2014) suggested that ceratophryids diversified early in semiarid environments, and three independent transformations resulted in C. aurita, C. ornata, and C. cornuta, which occupy tropical or temperate humid areas. In this context, it seems possible that ancestral short larval periods may have lengthened along with habitat diversification. Morphological and heterochronic shifts in embryonic trajectories also seem to be ancestral states initially linked to xeric environments, but unlike duration of larval development, they are likely maintained across species and not correlated with environmental changes. Similarly, the production of a cocoon of dead skin during estivation in species developing in humid areas was discussed as a plesiomorphic feature in Ceratophryidae and in other anuran radiations associated to arid/semiarid environments (Faivovich et al., 2014).

Accelerated growth rates are related to unpredictable environmental conditions during which a sudden explosion of trophic resources may increase proportion of proteins in diets, thereby promoting growth and development (Kupferberg, 1997). Accordingly, specialized feeding habits such as carnivory and cannibalism frequently occur in tadpoles of species inhabiting dry environments. Among ceratophryids, larvae of Chacophrys pierottii are omnivorous suspension-feeders, as are most generalized tadpoles (Quinzio et al., 2006), but larvae of Ceratophrys and Lepidobatrachus exploit different feeding resources and strategies. Tadpoles of Ceratophrys primarily prey on large items, such as invertebrates and other tadpoles, although they can also filter-feed on small items (Fabrezi et al., 2016; Vera Candioti, 2007). The tadpoles use their massive jaw sheaths to tear apart prey before ingesting it (Vera Candioti, 2005). In contrast, tadpoles of Lepidobatrachus are obligate predators of large prey that 
the larvae suction-feed whole (Ruibal \& Thomas, 1988). Tadpoles of the African Bullfrog Pyxicephalus ingest small fishes, invertebrates and other tadpoles, and also are capable of filtering small particles (Haas, 1999; Van Wyk, Kok, \& Du Preez, 1992). Among scaphiopodids, larvae of Scaphiopus have mainly herbivorous diets, whereas those of Spea can develop carnivorous morphs as a polyphenic response to environmental variables (e.g., Ledón-Rettig, Pfennig, \& NasconeYoder, 2008; Storz, 2004;).

Carnivorous tadpoles usually have a set of convergent morphological features, such as strong mouthparts, massive buccal depressor muscles, and short digestive tracts that often develop a section differentiated into a stomach with gastric digestion (e.g., Fabrezi, 2011; Ruibal \& Thomas, 1988). Our developmental data showed that in Ceratophrys, jaw sheaths differentiate early and rapidly acquire their robust, serrated larval configuration. Active feeding begins shortly thereafter, long before the oral disc is fully formed. This illustrates that tadpoles with an incomplete oral disc are capable of exotrophic feeding, but whether further development entails qualitative changes in diet remains to be explored. Similarly, herbivorous tadpoles of the scaphiopodid Spea intermontana do not acquire the larval labial tooth row formula until late, and differentiation of the anterior labium is slower than that of the posterior labium (Hall et al., 1997). In contrast, keratinization of jaw sheaths is delayed in Spea (after GS24) and the sequence of addition of labia ridges differs from that of Ceratophrys; in the latter, new labial ridges differentiate proximal to jaw sheaths, whereas in Spea, the direction varies between labia. The heterochronic shifts affecting different mouthparts of herbivorous Chacophrys and carnivorous Ceratophrys may reflect differences in oral disc performance in these tadpoles. Suspension-feeding requires fully formed labial tooth ridges with emerging labial teeth, but these structures are likely unnecessary in larvae that relay on robust jaw sheaths to feed on large prey. The pattern of active feeding preceding acquisition of a fully formed oral disc also occurs in herbivorous larvae of Spea and Chacophrys, thereby suggesting that differentiation of the digestive tract in fact may be the main constraint for the onset of exotrophic feeding in these groups.

Our observations of Chacophrys and Ceratophrys ornata are consistent with Bloom et al.'s (2013) discussion of morphogenesis of the digestive tract in ceratophryids. With some slight differences, tadpoles of Chacophrys have the same proportions and leftright disposition of mid- and foregut as in Xenopus laevis. The carnivorous tadpoles of Ceratophrys differ in having a transverse arrangement of the developing stomach and a shorter midgut. Embryos of Lepidobatrachus have a fundamental repatterning that begins with a distal formation of the gastroduodenal loop and ends with an extremely large, transverse larval stomach, and a short, almost uncoiled midgut. The intergeneric variation in morphogenesis of the digestive tract leads to larval morphologies that differ in gross structure, as well as in histomorphology and physiological properties linked to different functions (Fabrezi, 2011, 2016; Ulloa Kreisel, 2001, 2002). The experimental approach of Bloom et al. (2013) suggests that evolution in early morphogenesis of the gut in ceratophryids may have been promoted by modulations in retinoic acid and thyroid hormone signaling.
Some facets of embryonic morphology in ceratophryids seem independent of abiotic and biotic factors discussed here. First, the convergence of the stalk-like morphology of eggs of Chacophrys (but no other ceratophryid) and Spea multiplicata (Altig \& McDiarmid, 2007 ) is intriguing. Also, the pattern of gastrulation in ceratophryids is linked to an overall accelerated growth rate. According to del Pino et al. (2007), differences in timing of gene expression may result in the overlap between gastrulation and body lengthening (archenteron and neural tube extension). In embryos with slow development such as Gastrotheca riobambae, gastrulation takes about 2 weeks and body lengthening occurs postgastrulation (del Pino \& Loor-Vela, 1990). Conversely, in fast developers such as embryos of Xenopus and ceratophryids, gastrulation occurs in a few hours and overlaps with body lengthening (C. ornata, C. stolzmanni, and L. laevis; Amin et al., 2015; del Pino, 2010; Purcell \& Keller, 1993; Santillana Ortiz \& del Pino, 2009). Embryos of all species in our study also show some degree of overlap between the developmental events, as evidenced by elongated embryos with open blastopores.

Second, Type-A adhesive glands occur in all ceratophryid and scaphiopodid embryos (Hall et al., 1997), as well as in other anuran groups such as discoglossids, ranids, some hylids, and a small bufonid species group (Nokhbatolfoghahai et al., 2005; Pennati, Bolzern, Groppelli, Sotgia, \& de Bernardi, 2000; Vera Candioti et al., 2016). The putative synapomorphic delay in the bilateral division of the adhesive gland in the ancestor of Ceratophrys pends confirmation after the remaining species of the genus are examined. The late regression of these glands is puzzling, but the concomitant late regression of hatching glands that develop from the same prospective tissue (Pshennikova \& Voronina, 2012) suggests that the timing may reflect a developmental constraint unrelated to functional considerations.

Third, nearly three decades after the original description, the distinctive nasal appendix of Chacophrys pierottii remains intriguing. Faivovich and Carrizo (1992) described this structure in tadpoles up to GS38-39. Quinzio et al. (2006) redescribed the appendix based on examination of a series of wild larvae and pointed out that this structure reaches its apex of development at about GS30, after which it decreases in size until it has disappeared in most GS37 tadpoles. Likewise, captive embryos in our study lack the nasal appendix after GS25/29. However, a fourth series of Chacophrys collected in the field reveals exceedingly long appendices in larvae as old as GS38-39. Possibly environmental variations (especially those that can change significantly between field and lab conditions, such as feeding) may induce variation in presence and size of the appendix, and perhaps this exemplifies another case of environmental polyphenism such as that of scaphiopodids. A role in gas exchange in poorly oxygenated ponds was suggested for this structure (Fabrezi et al., 2019).

Last, the relationship between ploidy levels and developmental rates should be explored in Ceratophryidae, which is unusual in including multiple polyploid species (Faivovich et al., 2014). Polyploidy is an important evolutionary phenomenon that causes the wholegenome multiplication and a consequent genomic redundancy. Both higher and lower growth rates are expected in polyploid species, based on a positive correlation with the major RNA content, and a 
slower metabolic rate and longer cell cycle duration, respectively (Larkin, Tucci, \& Neiman, 2016; Otto, 2007). In a large-scale study of evolution of genome size in amphibians, Liedtke, Gower, Wilkinson, and Gomez-Mestre (2018) found that more rapid growth rates are associated with smaller genomes. Thus, it is noteworthy that Ceratophrys ornata and $C$. aurita have the longest larval developments reported (Honegger et al., 1985; Miranda-Ribeiro, 1923) and are two of the three octoploid species in the genus (Schmid, Haaf, \& Schempp, 1985; Soares-Scott, Trajtengertz, Soma, \& Beçak, 1988).

\section{5 | CONCLUSIONS}

The embryonic ontogeny of Ceratophryidae is phylogenetically and ecologically informative. Several features of embryonic morphology and heterochronic shifts in developmental sequences are shared by species for which data are available and are putative synapomorphies at different taxonomic levels. Some characters, including the arrangement and development of structures involved in gas exchange and the precocious differentiation of characters associated with an early onset of feeding and short development to metamorphosis, are likely plesiomorphic in the family. This is consistent with a pattern previously discussed in adult morphology and behavior, in which conserved characters seem to indicate an early diversification in semiarid environments. The morphology and ontogeny of the oral disc and the digestive tract in embryos are widely variable as are larval feeding habits. A final set of characters, from the conserved patterns of gastrulation and type of adhesive gland to the unique nasal appendix seem independent of habitat conditions and trophic niche, and raise further questions to be explored in the family.

\section{ACKNOWLEDGMENTS}

This work was supported by Agencia Nacional de Promoción Científica y Tecnológica funds (PICT 2015-2381 and 2017-2437). We thank LASEM (UNSa) and CISME (CONICET-UNT) for the scanning electron microscopy service, and J. S. Arias for his assistance with the analysis of developmental sequences. Two reviewers made valuable corrections and suggestions for the final manuscript.

\section{AUTHOR CONTRIBUTIONS}

J.G., D.B., and F.V.C. conceived and designed the project; J.G., D.B., C.S.C., and G.S.N. obtained the ontogenetic series; J.G. and F.V.C. analyzed the data; J.G. and F.V.C. wrote the manuscript; all the authors read and approved the final version of the manuscript.

\section{ORCID}

Jimena Grosso (D) https://orcid.org/0000-0002-1897-6621

\section{REFERENCES}

Alberch, P., Gould, S. J., Oster, G. F., \& Wake, D. B. (1979). Size and shape in ontogeny and phylogeny. Paleobiology, 5, 296-317. https://doi. org/10.1017/S0094837300006588
Altig, R. (2007). A primer for the morphology of anuran tadpoles. Herpetological Conservation and Biology, 2, 71-74.

Altig, R., \& McDiarmid, R. W. (2007). Morphological diversity and evolution of egg and clutch structure in amphibians. Herpetological Monographs, 21, 1-32. https://doi.org/10.1655/06-005.1

Amin, N. M., Womble, M., Ledón-Rettig, C., Hull, M., Dickinson, A., \& Nascone-Yoder, N. (2015). Budgett's frog (Lepidobatrachus laevis): A new amphibian embryo for developmental biology. Developmental Biology, 405, 291-303. https://doi.org/10.1016/j.ydbio.2015.06.007

Barrio, A. (1963). Consideraciones sobre comportamiento y "grito agresivo" propio de algunas especies de Ceratophrynidae (Anura). Physis, 24, 143-148.

Bloom, S., Ledón-Rettig, C., Infante, C., Everly, A., Hanken, J., \& NasconeYoder, N. (2013). Developmental origins of a novel gut morphology in frogs. Evolution \& Development, 15, 213-223. https://doi.org/10.1111/ ede.12035

Buchholz, D. R., \& Hayes, T. B. (2002). Evolutionary patterns of diversity in spadefoot toad metamorphosis (Anura: Pelobatidae). Copeia, 2002, 180-189. https://doi.org/10.1643/0045-8511(2002)002[0180:EPODIS] 2.0.CO; 2

Cei, J. M. (1980). Amphibians of Argentina. Monitore Zoologico Italiano, 2, 1-609.

del Pino, E. (2010). La gastrulación en ranas con diversos modos de reproducción. Revista Ecuatoriana de Medicina y Ciencias Biológicas, 31, 94-105. https://doi.org/10.26807/remcb.v31i1-2.46

del Pino, E. M., \& Loor-Vela, S. (1990). The pattern of early cleavage of the marsupial frog Gastrotheca riobambae. Development, 110, 781-789.

del Pino, E. M., Venegas-Ferrín, M., Romero-Carvajal, A., MontenegroLarrea, P., Sáenz-Ponce, N., Moya, I. M., ... Taira, M. (2007). A comparative analysis of frog early development. Proceedings of the National Academy of Sciences, 104, 11882-11888. https://doi.org/10.1073/ pnas.0705092104

Denver, R. J. (1998). Hormonal correlates of environmentally induced metamorphosis in the Western spadefoot toad, Scaphiopus hammondii. General and Comparative Endocrinology, 110, 326-336. https://doi.org/10.1006/gcen.1998.7082

Do Nascimento, F. A. C., Mott, T., Langone, J. A., Davis, C. A., \& de Sá, R. O. (2013). The genus Odontophrynus (Anura: Odontophrynidae): A larval perspective. Zootaxa, 3700, 140-158. https://doi.org/10. 11646/zootaxa.3700.1.5

Fabrezi, M. (2006). Morphological evolution of Ceratophryinae (Anura, Neobatrachia). Journal of Zoological Systematics and Evolutionary Research, 44, 153-166. https://doi.org/10.1111/j.1439-0469.2005. 00349.x

Fabrezi, M. (2011). Heterochrony in growth and development in anurans from the Chaco of South America. Evolutionary Biology, 38, 390-411. https://doi.org/10.1007/s11692-011-9128-5

Fabrezi, M. (2016). Epigénesis y epigenética: Ejemplos a partir de la morfología de los renacuajos. Cuadernos de Herpetología, 30, 5-15.

Fabrezi, M., \& Cruz, J. C. (2014). Ontogeny of the thyroid glands during larval development of South American horned frogs (Anura, Ceratophryidae). Evolutionary Biology, 41, 606-618. https://doi.org/ $10.1007 / \mathrm{s} 11692-014-9292-5$

Fabrezi, M., \& Quinzio, S. I. (2008). Morphological evolution in Ceratophryinae frogs (Anura, Neobatrachia): The effects of heterochronic changes during larval development and metamorphosis. Zoological Journal of the Linnean Society, 154, 752-780. https://doi. org/10.1111/j.1096-3642.2008.00420.x

Fabrezi, M., Quinzio, S. I., Goldberg, J., Cruz, J. C., Chuliver Pereyra, M., \& Wassersug, R. J. (2016). Developmental changes and novelties in ceratophryid frogs. EvoDevo, 7, 5. https://doi.org/10.1186/s13227016-0043-9

Fabrezi, M., Quinzio, S. I., Goldberg, J., Cruz, J. C., Chuliver Pereyra, M., \& Wassersug, R. J. (2019). In eLS (Ed.), Phenotypic variation through 
ontogeny: Ceratophryid frogs as a model. Chichester: John Wiley \& Sons. https://doi.org/10.1002/9780470015902.a0028510

Faivovich, J., \& Carrizo, G. R. (1992). Descripción de la larva de Chacophrys pierottii (Vellard, 1948) (Leptodactylidae, Ceratophryinae). Alytes, 10, 81-89.

Faivovich, J., Nicoli, L., Blotto, B. L., Pereyra, M. O., Baldo, D., Barrionuevo, J. S., ... Haddad, C. F. (2014). Big, bad, and beautiful: Phylogenetic relationships of the horned frogs (Anura: Ceratophryidae). South American Journal of Herpetology, 9, 207-228. https://doi.org/10.2994/SAJH-D-14-00032.1

Fernández, K., \& Fernández, M. (1921). Sobre la biología y reproducción de algunos batracios argentinos I. Cystignathidae. Anales de la Sociedad Científica Argentina, 91, 97-140.

Frost, D. R. (2019). Amphibian species of the world: An online reference. New York, USA: American Museum of Natural History. http:// research.amnh.org/herpetology/amphibia/index.html

Gosner, K. L. (1960). A simplified table for staging anuran embryos and larvae with notes on identification. Herpetologica, 16, 183-190.

Grainger, J. N. R. (1959). The effect of constant and varying temperatures on the developing eggs of Rana temporaria L. Zoologischer Anzeiger, 163, 267-277.

Grosso, J., Baldo, D., Cardozo, D., Kolenc, F., Borteiro, C., de Oliveira, M. I., ... Vera Candioti, F. (2019). Early ontogeny and sequence heterochronies in Leiuperinae frogs (Anura: Leptodactylidae). PLoS One, 14, e0218733. https://doi.org/10.1371/journal.pone.0218733

Haas, A. (1999). Larval and metamorphic skeletal development in the fastdeveloping frog Pyxicephalus adspersus (Anura, Ranidae). Zoomorphology, 119, 23-35. https://doi.org/10.1007/s004350050078

Hall, J. A., Larsen, J. H., Jr., \& Fitzner, R. E. (1997). Postembryonic ontogeny of the spadefoot toad, Scaphiopus intermontanus (Anura: Pelobatidae): External morphology. Herpetological Monographs, 11, 124-178. https://doi.org/10.1002/(SICI)1097-4687(199811)238: 2<179::AID-JMOR4>3.0.CO;2-6

Hanken, J. (1993). Model systems versus outgroups: Alternative approaches to the study of head development and evolution. American Zoologist, 33, 448-456.

Harrison, L. B., \& Larsson, H. C. (2008). Estimating evolution of temporal sequence changes: A practical approach to inferring ancestral developmental sequences and sequence heterochrony. Systematic Biology, 57, 378-387. https://doi.org/10.1080/10635150802164421

Honegger, R. E., Schneider, C., \& Zimmermann, E. (1985). Notizen zur Aufzucht von Schmuckhornfröschen Ceratophrys ornata (Bell, 1843) (Salientia: Leptodactylidae). Salamandra, 21, 70-80.

Jeffery, J. E., Bininda-Emonds, O. R., Coates, M. I., \& Richardson, M. K. (2005). A new technique for identifying sequence heterochrony. Systematic Biology, 54, 230-240. https://doi.org/10.1080/10635150590923227

Kupferberg, S. J. (1997). The role of larval diet in anuran metamorphosis. American Zoologist, 37, 146-159. https://doi.org/10.1093/icb/37.2.146

Larkin, K., Tucci, C., \& Neiman, M. (2016). Effects of polyploidy and reproductive mode on life history trait expression. Ecology and Evolution, 6, 765-778. https://doi.org/10.1002/ece3.1934

Ledón-Rettig, C. C., Pfennig, D. W., \& Nascone-Yoder, N. (2008). Ancestral variation and the potential for genetic accommodation in larval amphibians: Implications for the evolution of novel feeding strategies. Evolution \& Development, 10, 316-325. https://doi.org/10.1111/j. 1525-142X.2008.00240.x

Liedtke, H. C., Gower, D. J., Wilkinson, M., \& Gomez-Mestre, I. (2018). Macroevolutionary shift in the size of amphibian genomes and the role of life history and climate. Nature Ecology \& Evolution, 2, 1792-1799. https://doi.org/10.1038/s41559-018-0674-4

Miranda-Ribeiro, A. D. (1923). Observações sobre algumas phases evolutivas de Ceratophrys e Stombus. Archivos do Museu Nacional do Rio de Janeiro, 24, 201-213.

Natale, G. S., Alcalde, L., Herrera, R., Cajade, R., Schaefer, E. F., Marangoni, F., \& Trudeau, V. L. (2011). Underwater acoustic communication in the macrophagic carnivorous larvae of Ceratophrys ornata (Anura: Ceratophryidae). Acta Zoologica, 92, 46-53.

Nokhbatolfoghahai, M., \& Downie, J. R. (2005). Larval cement gland of frogs: Comparative development and morphology. Journal of Morphology, 263, 270-283. https://doi.org/10.1002/jmor.10305

Nokhbatolfoghahai, M., \& Downie, J. R. (2007). Amphibian hatching gland cells: Pattern and distribution in anurans. Tissue and Cell, 39, 225-240. https://doi.org/10.1016/j.tice.2007.04.003

Nokhbatolfoghahai, M., \& Downie, J. R. (2008). The external gills of anuran amphibians: Comparative morphology and ultrastructure. Journal of Morphology, 269, 1197-1213. https://doi.org/10.1002/jmor.10655

Nokhbatolfoghahai, M., Downie, J. R., Clelland, A. K., \& Rennison, K. (2005). The surface ciliation of anuran amphibian embryos and early larvae: Patterns, timing differences and functions. Journal of Natural History, 39, 887-929. https://doi.org/10.1080/00222930400002937

Ortiz, D. A., Almeida-Reinoso, D., \& Coloma, L. A. (2013). Notes on husbandry, reproduction and development in the Pacific horned frog Ceratophrys stolzmanni (Anura: Ceratophryidae), with comments on its amplexus. International Zoo Yearbook, 47, 151-162. https://doi.org/ 10.1111/j.1748-1090.2012.00193.x

Otto, S. P. (2007). The evolutionary consequences of polyploidy. Cell, 131, 452-462. https://doi.org/10.1016/j.cell.2007.10.022

Pennati, R., Bolzern, A. M., Groppelli, S., Sotgia, C., \& de Bernardi, F. (2000). The adhesive organs of Anura: A histological and molecular study. Italian Journal of Zoology, 67, 1-8. https://doi.org/10.1080/ 11250000009356287

Pshennikova, E. S., \& Voronina, A. S. (2012). Cement gland as the adhesion organ in Xenopus laevis embryos. Russian Journal of Developmental Biology, 43, 1-11. https://doi.org/10.1134/S1062360411040096

Purcell, S. M., \& Keller, R. (1993). A different type of amphibian mesoderm morphogenesis in Ceratophrys ornata. Development, 117, 307-317.

Pyron, R. A. (2014). Biogeographic analysis reveals ancient continental vicariance and recent oceanic dispersal in amphibians. Systematic Biology, 63, 779-797. https://doi.org/10.1093/sysbio/syu042

Quinzio, S. I., \& Fabrezi, M. (2014). The lateral line system in anuran tadpoles: Neuromast morphology, arrangement, and innervation. The Anatomical Record, 297, 1508-1522. https://doi.org/10.1002/ar.22952

Quinzio, S. I., Fabrezi, M., \& Faivovich, J. (2006). Redescription of the tadpole of Chacophrys pierottii (Vellard, 1948) (Anura, Ceratophryidae). South American Journal of Herpetology, 1, 202-210. https://doi.org/ 10.2994/1808-9798(2006)1[202:ROTTOC]2.0.CO;2

Ruibal, R., \& Thomas, E. (1988). The obligate carnivorous larvae of the frog, Lepidobatrachus laevis (Leptodactylidae). Copeia, 1988, 591-604. https://doi.org/10.2307/1445377

Salgado Costa, C. (2016). Desarrollo de un modelo experimental con larvas de Ceratophrys spp. (Anura: Ceratophryidae) para su aplicación en estudios ecotoxicológicos de plaguicidas: efectos sobre variables convencionales y bioacústicas. Tesis Doctoral, Universidad Nacional de La Plata, SEDICI, Buenos Aires. http://hdl.handle.net/10915/52069

Santillana Ortiz, J. D., \& del Pino, E. M. (2009). Características morfológicas de la gástrula en Ceratophrys stolzmanni (Anura: Ceratophryidae). Revista Ecuatoriana de Medicina y Ciencias Biológicas, 30, 50-57.

Schmid, M., Haaf, T., \& Schempp, W. (1985). Chromosome banding in Amphibia. IX. The polyploid karyotypes of Odontophrynus americanus and Ceratophrys ornata (Anura, Leptodactylidae). Chromosoma, 91, 172-184. https://doi.org/10.1007/BF00328215

Smith, K. K. (2001). Heterochrony revisited: The evolution of developmental sequences. Biological Journal of the Linnean Society, 73, 169-186. https://doi.org/10.1111/j.1095-8312.2001.tb01355.x

Soares-Scott, M. D., Trajtengertz, I., Soma, M., \& Beçak, M. L. (1988). C and $\mathrm{AgAs}$ bands of the octaploid untanha frog Ceratophrys dorsata (C. aurita) (8n = 104, Amphibia, Anura). Brazilian Journal of Genetics, 11, 625-631.

Storz, B. L. (2004). Reassessment of the environmental mechanisms controlling developmental polyphenism in spadefoot toad tadpoles. Oecologia, 141, 402-410. https://doi.org/10.1007/s00442-004-1672-6 
Thibaudeau, D. G., \& Altig, R. (1988). Sequence of ontogenetic development and atrophy of the oral apparatus of six anuran tadpoles. Journal of Morphology, 197, 63-69. https://doi.org/10.1002/jmor. 1051970106

Trudeau, V. L., Somoza, G. M., Natale, G. S., Pauli, B., Wignall, J., Jackman, P., ... Schueler, F. W. (2010). Hormonal induction of spawning in 4 species of frogs by coinjection with a gonadotropinreleasing hormone agonist and a dopamine antagonist. Reproductive Biology and Endocrinology, 8, 36.

Ulloa Kreisel, Z. E. (2001). Metamorfosis del aparato digestivo de larvas carnívoras de Ceratophrys cranwelli (Anura: Leptodactylidae). Cuadernos de Herpetología, 14, 105-116.

Ulloa Kreisel, Z. E. (2002). Características morfológicas del tubo digestivo en larvas carnívoras de Lepidobatrachus llanensis (Anura: Leptodactylidae). Acta Zoológica Lilloana, 46, 31-38.

Van Wyk, J. C. P., Kok, D. J., \& Du Preez, L. H. (1992). Growth and behaviour of tadpoles and juveniles of the African bullfrog Pyxicephalus adspersus Tschudi, 1838. The Journal of the Herpetological Association of Africa, 40, 56-56. https://doi.org/10.1080/04416651.1992. 9650326

Vera Candioti, M. F. (2005). Morphology and feeding in tadpoles of Ceratophrys cranwelli (Anura: Leptodactylidae). Acta Zoologica, 86, 1-11. https://doi.org/10.1111/j.0001-7272.2005.00178.x

Vera Candioti, M. F. (2007). Anatomy of anuran tadpoles from lentic water bodies: Systematic relevance and correlation with feeding habits. Zootaxa, 1600, 1-175. https://doi.org/10.2307/1563645

Vera Candioti, F., Grosso, J., Haad, B., Pereyra, M. O., Bornschein, M. R., Borteiro, C., ... Baldo, D. (2016). Structural and heterochronic variations during the early ontogeny in toads (Anura: Bufonidae). Herpetological Monographs, 30, 79-118. https://doi.org/10.1655/ HERPMONOGRAPHS-D-16-00004.1

Wen, L., Shibata, Y., Su, D., Fu, L., Luu, N., \& Shi, Y. B. (2017). Thyroid hormone receptor $\alpha$ controls developmental timing and regulates the rate and coordination of tissue-specific metamorphosis in Xenopus tropicalis. Endocrinology, 158, 1985-1998.

Zeng, C., Gomez-Mestre, I., \& Wiens, J. J. (2014). Evolution of rapid development in spadefoot toads is unrelated to arid environments. PLoS One, 9, e96637. https://doi.org/10.1371/journal.pone.0096637

Zweifel, R. G. (1968). Reproductive biology of anurans of the arid Southwest, with emphasis on adaptation of embryos to temperature. Bulletin of the American Museum of Natural History, 140, 1-64.

\section{SUPPORTING INFORMATION}

Additional supporting information may be found online in the Supporting Information section at the end of this article.

How to cite this article: Grosso J, Baldo D, Costa CS, Natale GS, Candioti FV. Embryonic ontogeny of three species of Horned Frogs, with a review of early development in Ceratophryidae. Journal of Morphology. 2019;1-16. https:// doi.org/10.1002/jmor.21076 